\title{
SEISMIC PERFORMANCE OF AN EXISTING RC STRUCTURE RETROFITTED WITH BUCKLING RESTRAINED BRACES
}

\author{
P. Castaldo ${ }^{1}$, E. Tubaldi ${ }^{2}$, F. Selvi ${ }^{3}$, L. Gioiella ${ }^{4}$ \\ ${ }^{1}$ Department of Structural, Geotechnical and Building Engineering (DISEG), Politecnico di Torino, \\ Turin, Italy (corresponding author). e-mail: paolo.castaldo@polito.it \\ ${ }^{2}$ Department of Civil and Environmental Engineering, University of Strathclyde, \\ Glasgow, Scotland. e-mail: enrico.tubaldi@ strath.ac.uk \\ ${ }^{3}$ Department of Structural, Geotechnical and Building Engineering (DISEG), Politecnico di Torino, \\ Turin, Italy. e-mail: federico.selvi@polito.it \\ ${ }^{4}$ School of Architecture and Design SAAD, University of Camerino, Ascoli Piceno, Italy. \\ e-mail: laura.gioiella@unicam.it
}

\begin{abstract}
The use of buckling restrained braces (BRBs) represents one of the best solutions for retrofitting or upgrading the numerous existing reinforced concrete framed buildings in areas with a high seismic hazard. This study investigates the effectiveness of BRBs for the seismic retrofit of reinforced concrete (RC) buildings with masonry infills. For this purpose, an advanced non-linear threedimensional model of an existing building in L'Aquila is developed in OpenSees, by accounting for the effect of infill walls through an equivalent strut approach, and by using a recently developed hysteretic model for the BRBs. The seismic performance of the building before and after the retrofit with BRBs is evaluated by performing both non-linear static analyses and incremental dynamic analyses under a set of real ground motion records. Seismic demand hazard curves are built for different response parameters before and after the retrofit, by accounting for and by disregarding the contribution of the infill walls. The study results shed light on the effect of the BRBs and of the infill walls on the seismic performance of the various components of the system, and on the effectiveness of the retrofit with BRBs for a real case study.
\end{abstract}

Keywords: seismic demand hazard curves, buckling restrained braces, capacity, reinforced concrete frame, masonry infill walls.

\section{INTRODUCTION}

Among the different solutions available to enhance the performance of existing structures, a great variety of passive energy dissipation systems [1]-[2] has been proposed in the last decades. These systems are usually classified as hysteretic dampers, viscoelastic dampers, viscous fluid dampers [3] and friction dampers [4]. Buckling restrained braces (BRBs) are hysteretic dampers that constitute one of the most efficient system for adding stiffness, strength and energy dissipation capacity to a structure [5]-[7]. The effectiveness of these devices has been proven by many experimental tests and numerical simulations, and numerous applications to existing buildings have been documented in the literature (e.g., [8]-[11]). BRBs consist of a steel core placed inside a steel tube filled with a concrete material [12]. The confinement provided by the concrete prevents the buckling of the steel core in compression and ensures that the damper exhibits a similar behaviour in tension and in compression [13]. According to numerous experimental tests, BRBs exhibit a stable hysteretic behaviour with a high-energy dissipation capacity, up to ductility levels higher than 20 [14]-[15]. 
Many studies in the literature have proposed methodologies for the design of BRBs for retrofitting existing frames and have evaluated the performance of the retrofit with deterministic approaches (e.g., [16]-[18]). However, very few works have analyzed the performance of buildings retrofitted with BRBs by employing probabilistic approaches accounting for the effect of the uncertainties inherent to the seismic input. Among these, Guneysi [19] investigated the application of BRBs for seismic retrofitting of steel moment resisting framed buildings. Fragility curves were developed using the maximum interstorey drift ratio as engineering demand parameter (EDP), and were used to compare the performances of the bare frame, the frame retrofitted with conventional braces, and the frame retrofitted with BRBs. Freddi et al. [6] proposed a probabilistic framework, based on the use of component and system fragility curves, to evaluate the effectiveness of BRBs for retrofitting reinforced concrete (RC) frames with low ductility capacity. These studies have neglected the influence of masonry infill walls that are often present and interact with the RC frame. However, the infills may affect the performance of the structure and of the retrofit system, by providing a contribution in terms of stiffness and energy dissipation. This was observed on studies considering other dissipative systems (e.g., [20]). Moreover, important EDPs, such as the absolute accelerations and residual drifts, were disregarded. Adding stiffness and strength to a frame through the BRBs often leads to an increase rather than a decrease of absolute accelerations, due to the reduction of the vibration period, and this may affect the performance of acceleration-sensitive non-structural building components. Furthermore, it is widely acknowledged that the main drawback of BRBs is their low post-yield stiffness, which may result in excessive residual inter-storey drifts in structures equipped with them [21]-[23]. Thus, an assessment of the effectiveness of the retrofit should also account for the response in terms of these two EDPs.

Finally, previous studies on the performance of buildings retrofitted with BRBs have employed simplified models of the BRBs with essentially elasto-plastic behaviour and kinematic hardening. However, more sophisticated constitutive models should be considered to properly account for the specific features of the behaviour of these devices that emerged in numerous experimental tests [12],[24]-[25]. These include the significant role of isotropic hardening and the asymmetry in the yield force in compression with respect to that in tension [12],[24]. The cumulative plastic deformations in the BRBs, that may control the failure of these devices due to low-cycle fatigue, need also to be monitored [26]-[31].

The aim of this work is to evaluate the effectiveness of buckling restrained braces for retrofitting an existing RC building, by considering the influence of the infill walls and by employing an advanced model of BRBs and a wide range of EDPs for monitoring the performance of the building components and of the BRBs. For this purpose, an existing RC building located in L'Aquila, damaged by the 2009 earthquake, is used as case study. First, a non-linear three-dimensional model of the existing RC building is defined in OpenSees [32], by simulating the infill walls with strut elements. A widely employed procedure based on pushover analyses and N2 method [33] is employed to design the braces. Specifically, the bracing system is designed by disregarding the effect of infill walls and with the target objective of achieving a maximum interstorey drift ratio of $1.5 \%$ under the life safety limit state design seismic action [34] for the site (return period of 475 years). Successively, the seismic performance of the retrofitted bare/infilled building is evaluated by performing both non-linear static analyses and incremental dynamic analyses under a set of real ground motion records. Seismic fragility and demand hazard curves of the building are derived considering multiple EDPs. These include the maximum and residual interstorey drifts, the absolute accelerations and the maximum and cumulative ductility capacity of the BRBs.

The capability of the dissipative bracing system in enhancing the performance of structural and nonstructural components of the frame is assessed by evaluating the results in terms of seismic demand hazard curves, providing the annual rate exceeding different demand levels. The comparison of the results obtained for the models with the infills also sheds light on the influence of the infill walls on the performance of the system retrofitted with BRBs. 


\section{CASE STUDY: DESCRIPTION AND MODELLING}

The case study (Figure 1) is a reinforced concrete frame building located in L'Aquila (Italy), built in 1984 that is representative of many RC structures built in Italy before the introduction of modern seismic codes and designed for gravity loads only, without any seismic detailing. The building is composed of five stories with a height of $2.8 \mathrm{~m}$ at the ground storey and of $3 \mathrm{~m}$ at the other storeys. Figure 1 describes the plan configuration of the frame, with an overall length of $25.30 \times 10.85 \mathrm{~m}$ along the horizontal (X) and vertical (Y) directions, respectively. A reinforced concrete staircase is located centrally in the lower part of the building. The frame columns have a rectangular cross section with dimensions $35 \times 60 \mathrm{~cm}$ at the ground floor and 30x60 $\mathrm{cm}$ at the other floors, whereas the columns that support the stair landing have the same rectangular cross section of $25 \times 60 \mathrm{~cm}$ at each floor. The beams along the $Y$ direction are deep beams with various rectangular sections: $35 \times 50 \mathrm{~cm}, 30 \times 50 \mathrm{~cm}$ and $25 \times 50 \mathrm{~cm}$. The beams along the $\mathrm{X}$ direction are deep beams with rectangular section equal to $25 \times 50 \mathrm{~cm}$ for the external frames, whereas they are flat slab beams with rectangular section equal to $60 \times 20 \mathrm{~cm}$ for the internal one. The stairs consist of $20 \mathrm{~cm}$ concrete slabs supported by $40 \times 20 \mathrm{~cm}$ flat beams.

The properties of materials used for the structural components of the frame have been evaluated via a campaign of destructive in-situ tests. In particular, the concrete material behavior was evaluated based on 16 compressive tests on concrete cores extracted from the RC frame elements. The steel properties of the ribbed bars were evaluated based on tensile strength tests executed on two specimens, picked up from structural members and declared as FeB38k. Table 1 reports the average mechanical properties obtained from the tests. The results of the tests performed on concrete cores have been post-processed in accordance to the expression proposed by the Concrete Society 1987 [35], which takes into account for the influence due to the extraction process, for the slenderness of the core and for the eventual presence of rebars. The results have been considered representative for the unconfined concrete and reinforcement steel, while the characteristics of the confined concrete are obtained using a specific model [36] as described in the following. With regards to concrete, $f_{c}$ denotes the compressive strength, $E_{c}$ the elastic modulus, $\varepsilon_{c}$ and $\varepsilon_{c u}$ the peak and ultimate deformations, calculated according to [37], and $f_{c u}$ the ultimate strength. With regards to steel, $f_{s y}$ is the yield stress, $E_{s}$ the elastic modulus, and $b$ the post-elastic to elastic stiffness hardening ratio.

Table 1. Mechanical properties of unconfined concrete and steel reinforcement.

\begin{tabular}{ccccc|cc|c}
\hline \multicolumn{5}{c|}{ Unconfined concrete } & \multicolumn{3}{c}{ Steel } \\
\hline$f_{c m}\left[\mathbf{N} / \mathbf{m m}^{2}\right]$ & $\varepsilon_{c}[-]$ & $f_{c u}\left[\mathbf{N} / \mathbf{m m}^{2}\right]$ & $\varepsilon_{c u}\left[\mathbf{N} / \mathbf{m m}^{2}\right]$ & $E_{c}\left[\mathbf{N} / \mathbf{m m}^{2}\right]$ & $f_{s y}\left[\mathbf{N} / \mathbf{m m}^{2}\right]$ & $E_{s}\left[\mathbf{N} / \mathbf{m m}^{2}\right]$ & $b[-]$ \\
\hline 21.6 & 0.0018 & 11.57 & 0.0035 & 27717.8 & 430.7 & 206000 & 0.01 \\
\hline
\end{tabular}

Figure 2 reports the distribution of the infill walls at all the elevations of the building; the scale of the colours identifies the thickness and presence or absence of openings in the infill panels. It is worth to note that only the infills located within the frames, as highlighted in Figure 2, are taken into account in the numerical model of the building and that their distribution is quite irregular, especially at the ground level where the garages are located. For what concerns the mechanical properties of the infills, the exterior panels, located along the perimeter of the building, have thickness equal to $20 \mathrm{~cm}$ and a reduced percentage of the holes in the bricks. Thus, they are classified as "intermediate infills" according to Decanini et al. [38]. The panels adjacent the stairwell are characterized by a reduced thickness $(18 \mathrm{~cm})$ and a higher percentage of the holes in the bricks, and thus they are denoted as "weak infills". For all the infill walls, the reported thickness refers only to the portion of the infill panels that provides a contribution in terms of stiffness in the in-plane behaviour and which is realized with bricks. Table 2 reports the mechanical properties of the masonry in terms of compressive strength $\sigma_{\mathrm{m} 0}$, shear strength evaluated through diagonal compressive test $\tau_{\mathrm{m} 0}$, and elastic modulus 
$E_{\mathrm{m}}$; the parameter values are based on [38]. The infills classification together with the mechanical properties of the masonry, reported later on, are calibrated based on experimental tests available in literature, as described in [38].

Table 2. Masonry infills description and mechanical properties.

\begin{tabular}{c|ccc}
\hline Infills type & $\boldsymbol{\sigma}_{\boldsymbol{m} \boldsymbol{0}}[\mathbf{M P a}]$ & $\boldsymbol{\tau}_{\boldsymbol{m} \boldsymbol{0}}[\mathbf{M P a}]$ & $\boldsymbol{E}_{\boldsymbol{m}}[\mathbf{M P a}]$ \\
\hline Weak & 1.2 & 0.2 & 1050 \\
Intermediate & 2.1 & 0.4 & 1880 \\
\hline
\end{tabular}

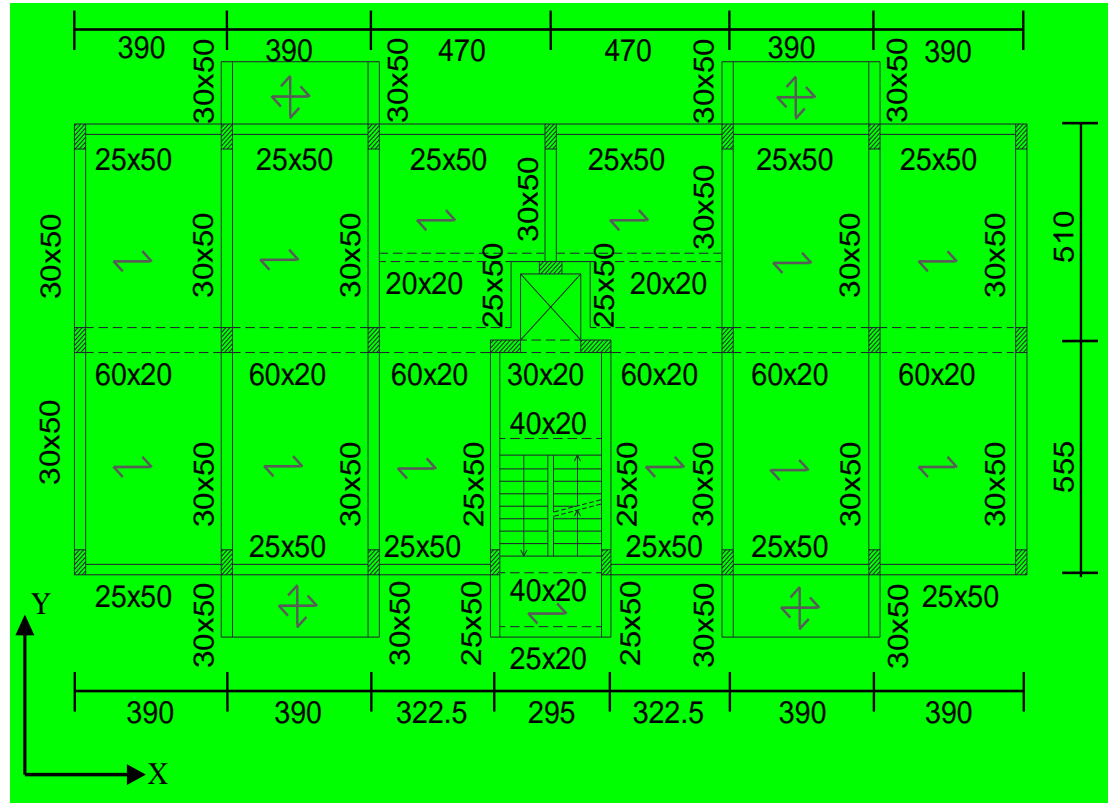

Figure 1. Schematic plan configuration of the building. (Dimensions in $\mathrm{cm}$ )
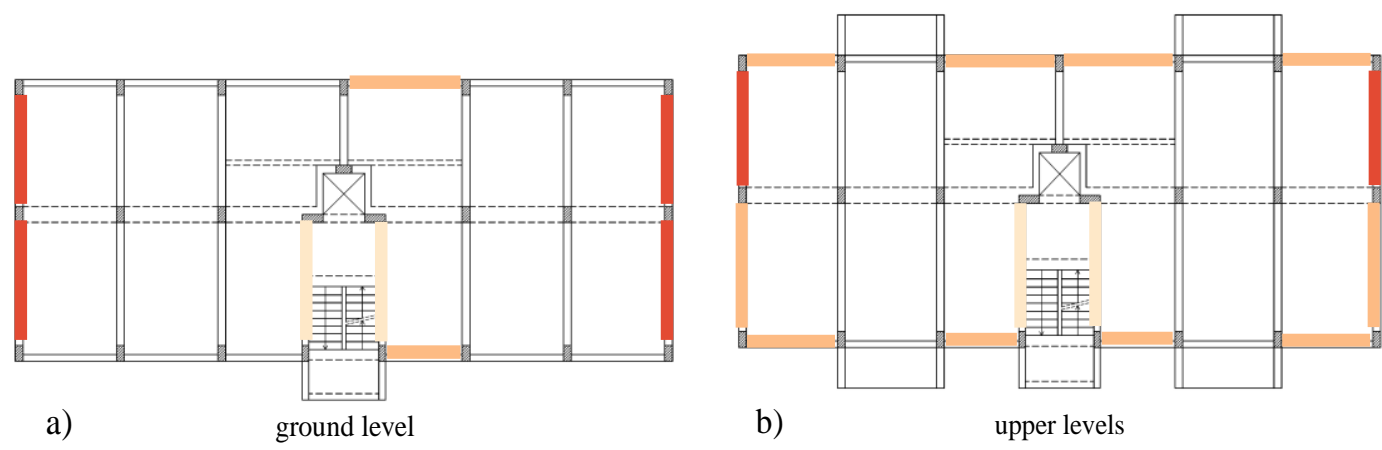

Thickness $20 \mathrm{~cm}$, no openings

Thickness $20 \mathrm{~cm}$, with openings

Thickness $18 \mathrm{~cm}$, with openings

Figure 2. Features and distribution of the infill walls at ground floor a) and at floors from 1 to 4 b).

The building is located in L'Aquila (Italy), with geographical coordinates Lon. $=13.394^{\circ}$ and Lat. $=42.36^{\circ}$, on a soil of class D and topographical category T1, according to [34]. Figure 3 shows the code elastic response spectra in terms of accelerations and displacements for different limit states and relevant return periods (i.e., Operational -30 years, Damage -50 years, Life Safety -475 years, Near Collapse - 975 years) assuming an inherent damping factor of 5\%, respectively. 

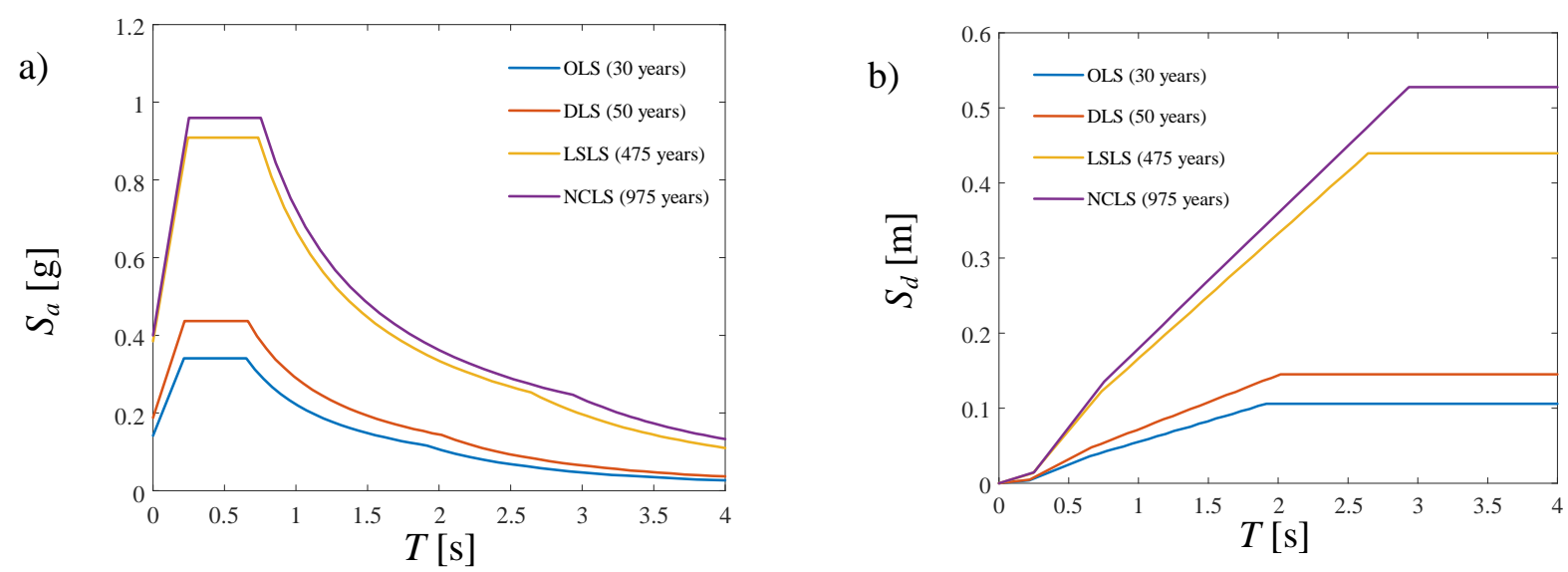

Figure 3. Code elastic response spectra in terms of accelerations a) and displacements b).

Figure 4 shows the numerical model of the RC frame developed in OpenSees [32], which employs "beam with hinges" elements [39] to describe the nonlinear hysteretic response of beams and columns and elastic beam elements for the stairwells. The beam-column joints are described by beam elements with very high stiffness whereas the in-plane rigid floor slab is described by a diaphragm constraint at each floor. This latter assumption is in line with the requirement of the Italian Seismic Code [34] to consider a floor as a rigid diaphragm. In the "beam with hinges" elements, the inelastic behaviour is concentrated over specified hinge lengths $L_{p i}$ and $L_{p j}$ at the two element ends while, a linear elastic behaviour is assigned to the central portion. The lengths of the plastic hinges are defined as a function of the shear span $L_{V}$, assumed equal to the half element length, and of the product between the bar yield strength and diameter $f_{s y} d_{b}[40]$ :

$$
L_{p}=0.12 L_{V}+0.014 \alpha_{s l} f_{s y} d_{b}
$$

where $\alpha_{s l}$ is a variable that can assume the value 1 if the slippage of the reinforcement bars from the anchorage zone beyond the end section is possible or 0 if is not.

In the plastic hinge zone, the behaviour of concrete is described by the nonlinear degrading Concrete02 material model [32], with tensile strength set to $0.1 f_{c m}$ and a linear tension softening.

The effect of the confinement of the concrete core fibers of beams and columns is taken into account by modifying the concrete constitutive law as suggested by [36]. The compressive strength of the confined concrete increases thanks to the compressive effect provided by the stirrups and the longitudinal reinforcement and can be evaluated as:

$$
f_{c c}^{\prime}=f_{c m}\left(-1.254+2.254 \sqrt{1+\frac{7.94 f_{l}^{\prime}}{f_{c m}}}-2 \frac{f_{l}^{\prime}}{f_{c m}}\right)
$$

where $f_{c m}$ is the compressive strength of the unconfined concrete (Table 1) and $f_{l}^{\prime}$ depends on the geometry of the section and of the reinforcements as explained in [36]. The ultimate compressive strain, $\varepsilon_{c u}$, corresponds to the rupture of the first hoop and can be found based on an energy balance approach [36]. The confinement differs for each section, since it depends on the dimensions, and amount of longitudinal bars and stirrups. Thus, different values of $f_{c c}^{\prime}$, crushing strength and $\varepsilon_{c u}$ are obtained for the various sections.

The behaviour of steel reinforcement is described by using a uniaxial bilinear constitutive law with kinematic hardening (Steel01 in OpenSees [32]). Concrete cracking is taken into account by considering an effective flexural stiffness for the elastic part of each beam and column element. This 
stiffness is evaluated by means of moment-curvature analysis of the sections at the extremes of the elements, for the axial force level induced by the dead loads (zero axial load in case of beams).

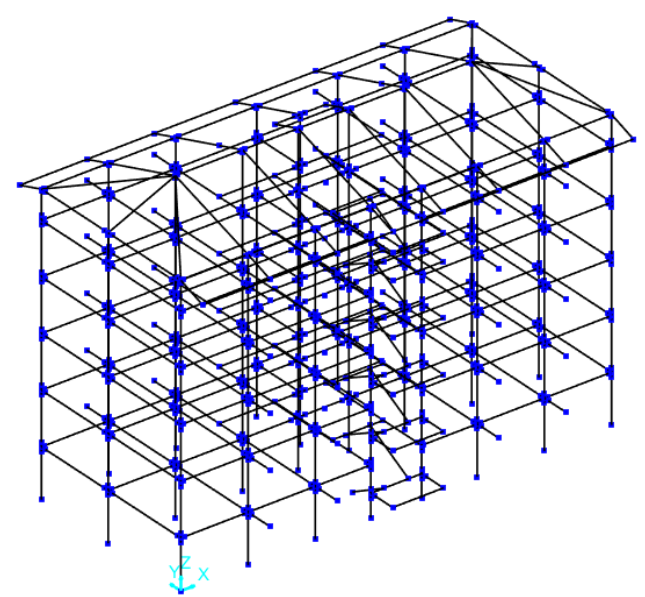

a)

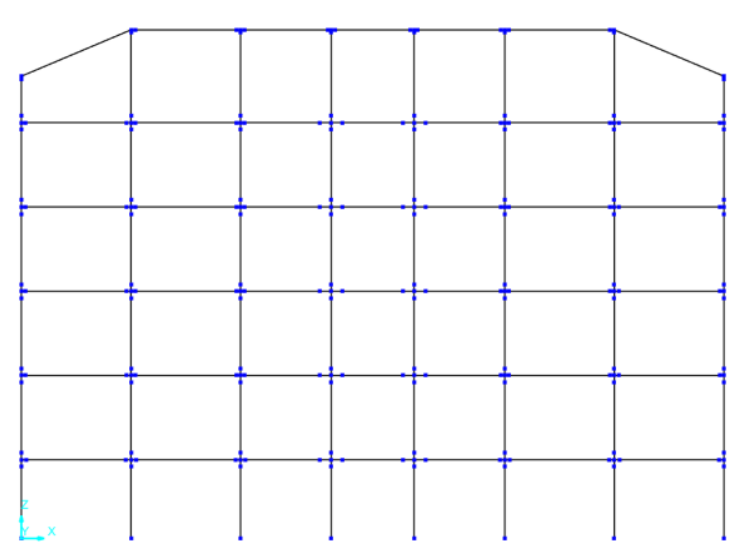

c)

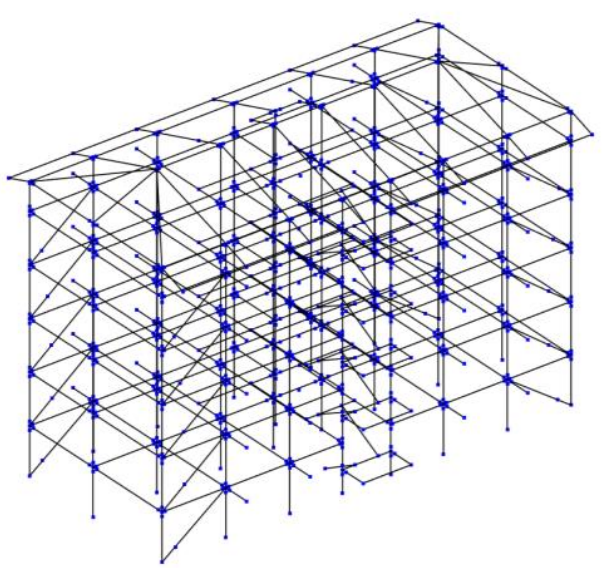

b)

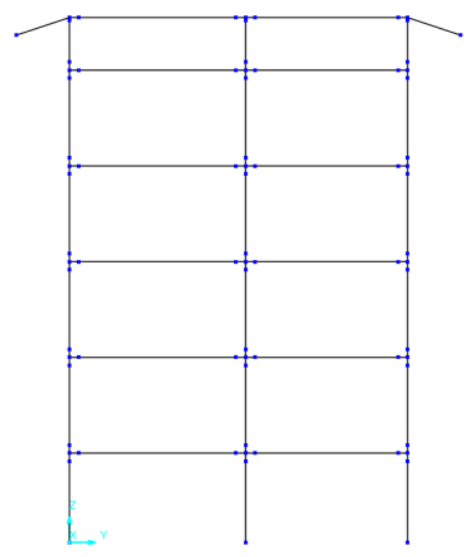

d)

Figure 4. Numerical model of the RC building in OpenSees a) 3D view with no infills, b) 3D view with BRB and without infills, c) view of the central alignment along the $\mathrm{X}$ direction, $\mathrm{d}$ ) view of the first alignment of the $\mathrm{Y}$ direction.

Using the function "MinMax material" of OpenSees [32], material failure can be simulated in the fibers of the RC sections by setting the stresses to zero once a prefixed strain threshold value is attained. The threshold for the confined concrete fibers, $\varepsilon_{c u}$, depends on the concrete confinement according to the Mander model [36]. Since the values of $\varepsilon_{c u}$ do not exhibit a significant variability from section to section, for simplicity they have been assumed equal to -0.012 for all the sections. For the unconfined concrete of the cover of the cross sections, the strain threshold was set to -0.0035 . The rupture of the reinforcement bars, with a drop of the stress to zero, is assumed to occur at a strain of 0.075 , which is the required elongation at maximum force of reinforcing steel according to [34]. The system nonlinear geometrical behaviour is taken into account by considering secondorder P-delta effects.

In order to describe in a simplified way the in-plane interaction between the infill panels and the frame elements, the approach recommended in [41] is followed, by using two diagonal elements (Figure 5) for each infill. These diagonal elements are active only in compression. The forcedisplacement relationship of the diagonals is composed of four branches: a first linear elastic branch, a post-cracking phase up to the reaching of the maximum strength, a descending third branch that describes the post-peak strength deterioration until the attainment of the residual strength and displacement. After that, the curve continues horizontally. This behaviour is modelled in OpenSees [32] using link elements with a uniaxial bilinear hysteretic constitutive law with pinching of force 
and deformation along the axial direction, whose envelope is illustrated in Figure 6a. The effect of openings is taken into account by reducing the resisting force of the links, as suggested in [41]. The constitutive law of an intermediate infill panel with and without openings is depicted in Figure 6a. Figure $6 \mathrm{~b}$ shows the hysteretic behaviour assumed for an intermediate infill panel with and without openings.
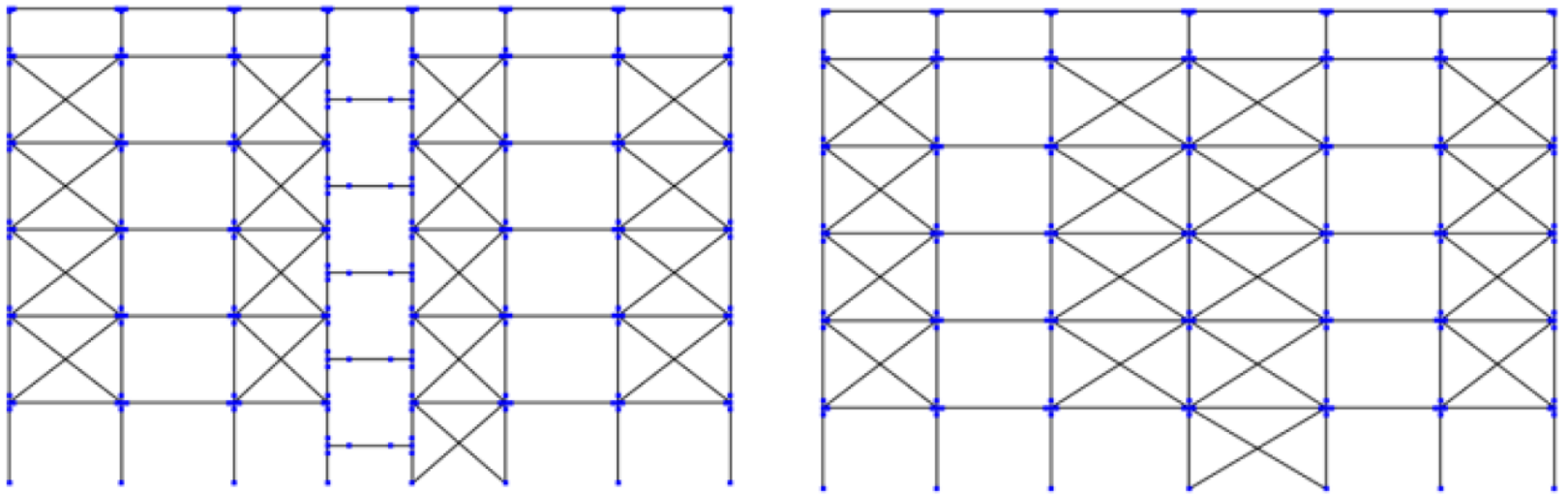

Figure 5. View of external building frames with infills panels described by diagonal brace elements.
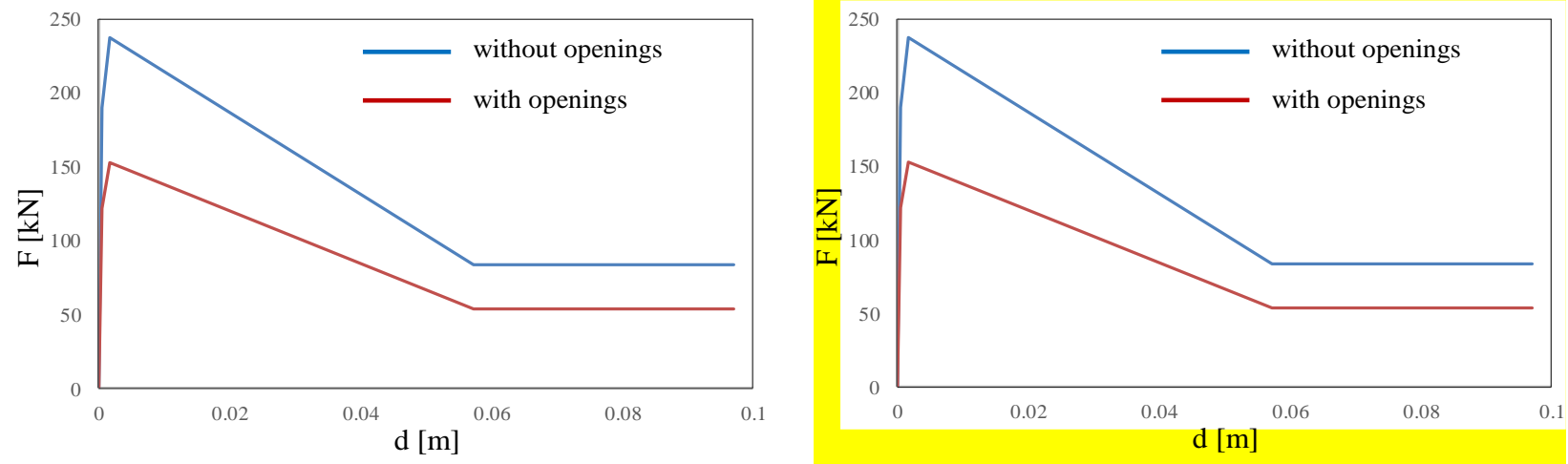

Figure 6. Force-displacement relationship (a) and hysteretic behaviour (b) of an intermediate infill with and without openings.

\section{DESIGN AND MODELLING OF THE HYSTERETIC DEVICES (BRBs)}

The method proposed by Dall'Asta et al. [16] is employed in this study to design the dissipative bracing system. According to this method, the dissipative bracing system and the existing frame are described as two elastic-perfectly plastic single-degree-of-freedom (SDOF) systems acting in parallel. The properties of the SDOF system equivalent to the existing frame are derived by performing a pushover analysis under a distribution of forces corresponding to its first vibration mode [33]. The capacity curve of the frame is replaced by an elastic perfectly-plastic one, which is obtained based on an energy equivalence criterion and is described by the initial stiffness $K_{f}$, the base shear capacity $V_{f}$, and the ductility capacity $\mu_{f_{c}}$ (Figure $7 \mathrm{a}$ ).

The properties of the bracing system depend on the properties of the diagonal braces at each storey. It is worth to recall that the diagonal dissipative braces considered here consist of two members in series, namely the BRB device and the over-strengthened brace. Only the first one undergoes plastic deformations, whereas the second is designed to remain elastic.

The distribution of the stiffness of the braces along the building height is assumed equal to the one of the frame in order to obtain a coupled system with the same first mode shape. Moreover, the braces are assumed to yield simultaneously when the structure vibrates according to the first mode.

The design ultimate displacement of the diagonal brace system can be assumed equal to that of the frame, in order to ensure simultaneous failure of both the frame and the braces. The capacity curve 
of the bracing system is idealized as an elastic-perfectly plastic curve, and described by few parameters that are the design variables: the initial stiffness $K_{d}$, the base shear capacity $V_{d}$, and ductility capacity $\mu_{d c}$, equal to that of the diagonal braces under the assumption of simultaneous yielding of the diagonal braces at all the storeys. It is noteworthy that the BRBs, and thus the bracing system, exhibit a more complicated behaviour, which however is simplified in the design stage.

It is worth to observe that, the model used for the analysis is a three-dimensional model as depicted in Figure 4 a)-d), nevertheless both the seismic input used for the following incremental non-linear dynamic analyses (IDAs) and the loads applied in the following pushover analyses involve only the $\mathrm{X}$ direction (see Figure 1), since it corresponds to the weak direction of the bare frame. This way, even if the seismic excitation is unidirectional, it is still possible to account for the actual distribution of the masses, including those of the infill walls. In the followings, therefore, only the retrofit of the frame along the $\mathrm{X}$ direction is considered. The results from the modal analysis of the bare frame for the first five vibration modes are summarized in Table 3, together with the mass participant factors (expressed in percentage) along the $\mathrm{X}$ and $\mathrm{Y}$ directions $\left(\boldsymbol{M}_{X}\right.$ and $\left.\boldsymbol{M}_{\mathbf{Y}}\right)$ and the torsional component too $\left(M_{\vartheta}\right)$. The coupling between the modal responses along the two directions is very low, while the mass participation factor of the first mode along the $\mathrm{X}$ direction is very high (i.e., 80.8\%).

Table 3. Vibration modes of the bare frame.

\begin{tabular}{ccccccc}
\hline Mode & Type & $\boldsymbol{\omega}[\mathbf{r a d} / \mathbf{s}]$ & $\boldsymbol{T}[\mathrm{s}]$ & $\boldsymbol{M}_{\boldsymbol{X}}[\boldsymbol{\%}]$ & $\boldsymbol{M}_{\boldsymbol{Y}}[\%]$ & $\boldsymbol{M}_{\boldsymbol{\vartheta}}[\%]$ \\
\hline $\mathbf{1}$ & Translational X & 7.388 & 0.850 & 80.80 & 0.000 & 0.511 \\
\hline $\mathbf{2}$ & Rotational & 9.371 & 0.670 & 0.530 & 0.776 & 78.790 \\
\hline $\mathbf{3}$ & Translational Y & 9.496 & 0.662 & 0.004 & 78.66 & 0.780 \\
\hline $\mathbf{4}$ & Translational X & 23.432 & 0.268 & 10.90 & 0.000 & 0.043 \\
\hline $\mathbf{5}$ & Rotational & 30.300 & 0.207 & 0.032 & 0.050 & 11.100 \\
\hline
\end{tabular}

The design procedure of the bracing system requires the evaluation of the bare frame capacity curve along the $X$ direction by means of a nonlinear static (pushover) analysis. The lateral load pattern for the pushover analysis is determined for a distribution of the loads proportional to the first vibration mode of the structure. The control node is the centre of mass of the fifth floor. Figure 7a shows the capacity curve of the equivalent SDOF system and its bi-linearization according to the Italian code [34]. These curves are expressed in terms of $d^{*}$ and $V^{*}$, which are obtained dividing the displacement of the control node and the base shear of the MDOF system by the modal participation factor $\Gamma=\sum m_{i} u_{i} / \sum m_{i} u_{i}^{2}$ of the first vibration mode. The ductility capacity of the frame is $\mu_{f c}=3.73$, corresponding to a maximum inter-storey drift ratio of $2.3 \%$ for the bare frame model.
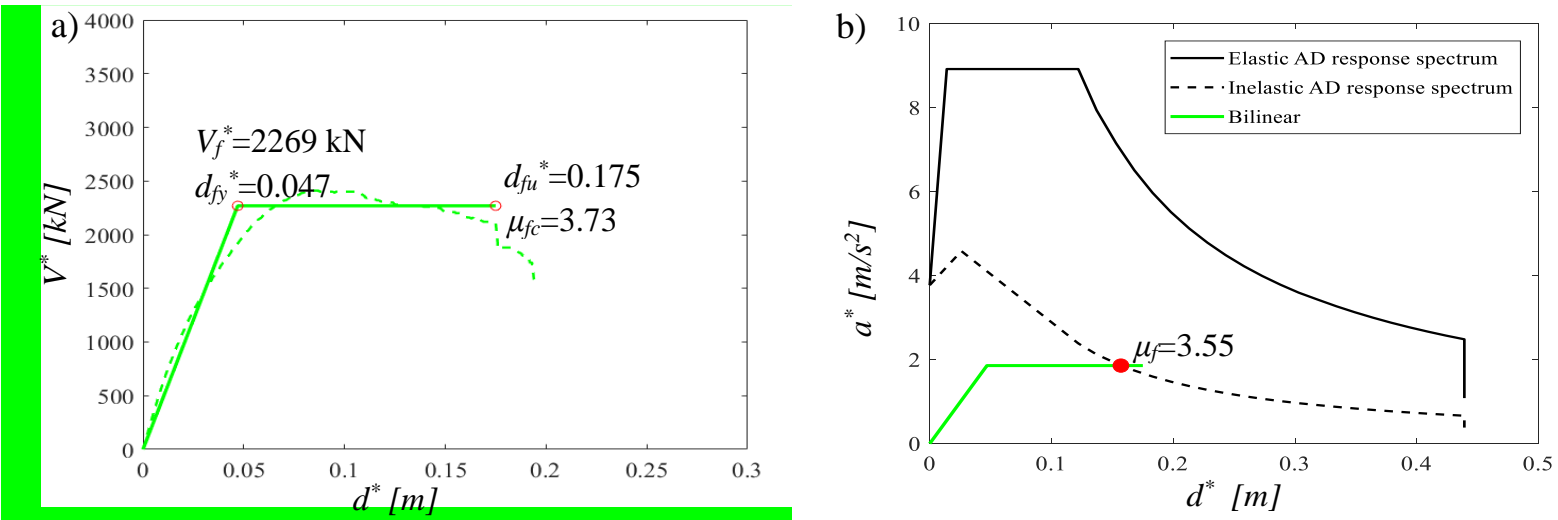

Figure 7. a) Capacity curve of the SDOF system equivalent to the bare frame and its bi-linearization and b) comparison between the seismic demand and capacity for the bare frame. 
Figure $7 \mathrm{~b}$ compares, in the acceleration-displacement plane, the elasto-plastic capacity curve of the bare frame and the seismic demand for the life safety limit state according to the N2 method. The values of the acceleration $a^{*}$ of the capacity curve are obtained by dividing the forces $V^{*}$ by the equivalent mass $m^{*}=\sum m_{i} u_{i}$ of the SDOF system. It can be seen that the ductility demand $\mu_{f}=3.55$ is quite close to the ductility capacity of the structure. Thus, the structure needs to undergo significant plastic deformations to withstand the seismic demand, leading to extended damage.

In order to reduce the seismic damage, the bracing system is added in parallel to the frame, and the target ductility demand of the frame under the design seismic input is assumed equal to $\mu_{f}=2.64$, corresponding to a maximum interstorey drift ratio (IDR) of $1.5 \%$.

The ductility capacity of the BRB devices and of the dissipative system are assumed respectively equal to $\mu_{0 c}=15$ and $\mu_{d c}=10$. It is noteworthy that the value of $\mu_{d c}$ is less than the value of $\mu_{0 c}$ due to the flexibility of the brace placed in series with the BRB device ([5],[16]). The base shear capacity of the BRB system must be equal to $V_{d}=900 \mathrm{kN}$ to obtain a design capacity curve of the coupled system (frame and BRBs system) that intersects the inelastic demand spectrum (Figure 8a-b). It is noteworthy that the base shear of the bracing system is only $39 \%$ of the base shear of the bare frame. Although a higher value could be chosen, by reducing the ductility demand of the frame, this would result in excessive forces transmitted to the columns adjacent to the bracing system, and an increase of their vulnerability [5]. Moreover, higher values of this ratio are generally associated with excessive interstorey residual drift levels, impairing reparability after major earthquake events, as also commented in [42]. In order to gain some insight into the amount of energy dissipated by the BRB system and by the frame, the area below the force-displacement curves of these two systems are calculated from Figure 8a. These areas amount to respectively to $100.44 \mathrm{KNm}$ and $177.60 \mathrm{kNm}$. Thus, the BRB system contributes to only to $36 \%$ of the total energy dissipated in the coupled system.
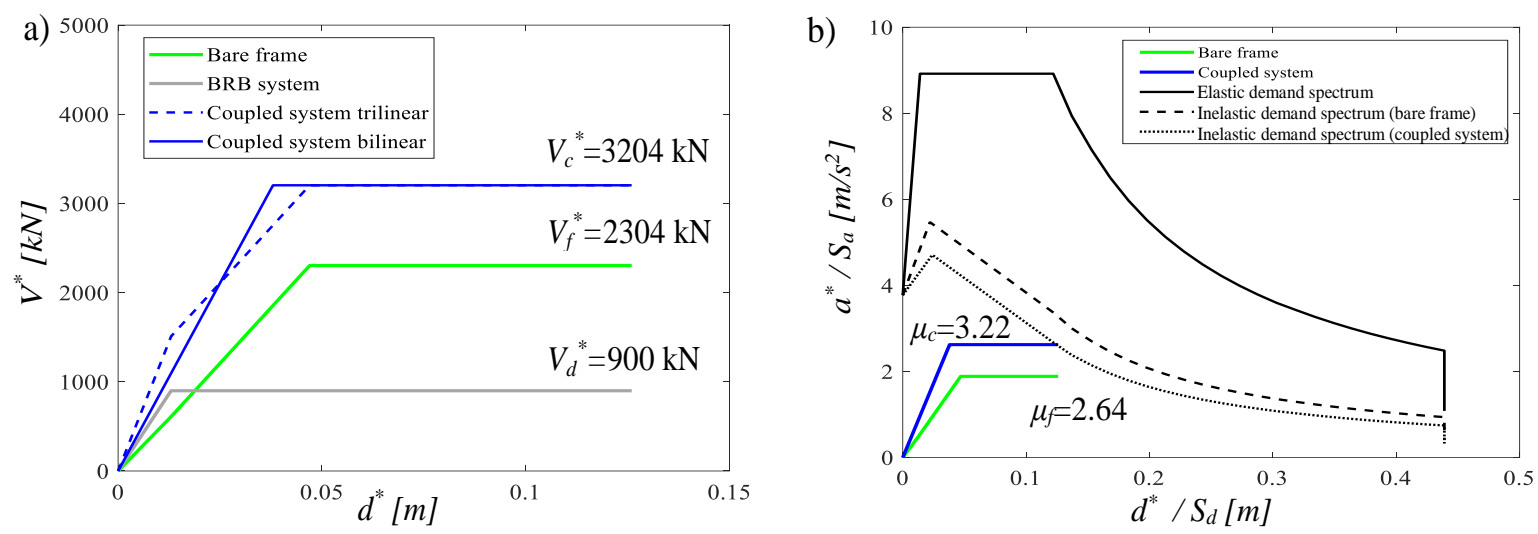

Figure 8. a) Design bilinear capacity curve of the SDOF system equivalent to the retrofitted frame and b) comparison between the seismic demand and capacity for the retrofitted frame.

Given the properties of the bracing system, the characteristics of the BRB devices and of the elastic braces at each storey can be determined by following the procedure described in Dall'Asta et al. [16] and they are reported in Table 4, where the properties of each bracing system at each level are listed. It is worth to recall that the design properties of the braces (initial stiffness $K_{d}^{i}$, yielding force $F_{d}^{i}$ and ductility capacity $\mu_{d c}^{i}$ where $i$ denotes the storey number) depend on the properties of the BRB device (initial stiffness $K_{0}^{i}$, yield force $F_{0}^{i}$ and ductility capacity $\mu_{0 c}^{i}$ ) and on the properties of the elastic brace (length $L_{b}^{i}$ and stiffness $K_{b}^{i}$ ). The brace length $L_{d}^{i}$ is equal to the sum of the BRB length $L_{0}^{i}$ and the elastic brace length $L_{b}^{i}$.In order to limit the axial forces transmitted to the columns adjacent to the braces, four diagonal braces are employed at each storey. The brace arrangement is shown in Figure 9 . 
Table 4. Mechanical properties of each dissipative brace, BRB and elastic brace at each storey.

\begin{tabular}{|c|c|c|c|c|c|c|c|c|c|c|c|}
\hline & \multicolumn{2}{|c|}{ Brace } & \multicolumn{4}{|c|}{ BRB } & \multicolumn{5}{|c|}{ Elastic brace } \\
\hline Storey & $F_{d} d$ & $K_{d}{ }^{i}$ & $\boldsymbol{K}_{0}^{i}$ & $F_{0}{ }^{i}$ & $A_{0}{ }^{i}$ & $L_{0}^{i}$ & $\boldsymbol{K}_{b}^{i}$ & $\boldsymbol{F}_{b}{ }^{i}$ & $A_{b}^{i}$ & $t_{b}{ }^{i}$ & $\boldsymbol{L}_{b}^{i}$ \\
\hline$[-]$ & {$[\mathrm{kN}]$} & {$[\mathrm{kN} / \mathrm{m}]$} & {$[\mathrm{kN} / \mathrm{m}]$} & [kN] & {$\left[\mathbf{m}^{2}\right]$} & [m] & {$[\mathrm{kN} / \mathrm{m}]$} & [kN] & {$\left[\mathbf{m}^{2}\right]$} & {$[\mathrm{mm}]$} & [m] \\
\hline 4 & 152 & 91404 & 142.18 & 152.05 & 608.19 & 898.3 & 255.93 & 1740 & 4901 & 10 & 4022 \\
\hline 3 & 235.6 & 91793 & 142.79 & 235.56 & 942.23 & 1385.7 & 257.02 & 1535 & 4326 & 10 & 3534 \\
\hline 2 & 299 & 95200 & 148.09 & 299.04 & 1196.14 & 1696.2 & 266.56 & 1452 & 4092 & 10 & 3224 \\
\hline 1 & 338 & 105238 & 163.7 & 337.99 & 1351.97 & 1734.3 & 294.67 & 1587 & 4470 & 10 & 3186 \\
\hline 0 & 343.8 & 188593 & 293.37 & 343.78 & 1375.14 & 984.4 & 528.06 & 3407 & 9597 & 10 & 3816 \\
\hline
\end{tabular}

The dissipative braces are modelled by using two elements (Figure 9): an elastic beam element for the elastic brace and a truss element for the BRB. The BRB is assigned the constitutive law of Zona et al. [30]. The parameters that influence the hardening and hysteresis of the elasto-plastic model can be calibrated based on experimental characterization tests carried out on BRB prototypes. In this study, the parameters reported in Zona et al. [30] and calibrated on the experimental tests of Tremblay et al. [43] are considered. Figure 10 shows the capacity curve evaluated by performing the nonlinear static analysis of the retrofitted structure, and the corresponding equivalent bilinear curve. The capacity curve is truncated at a value of the displacement equal to $0.15 \mathrm{~m}\left(d^{*}=0.135 \mathrm{~m}\right)$, corresponding to an IDR of $1.5 \%$ for the frame and a ductility capacity $\mu_{c}=3.22$. The ductility of the coupled system is much higher than that of the frame $\left(\mu_{f}=2.64\right)$, thanks to the addition of the BRBs. Figure $10 \mathrm{~b}$ compares the elastic and inelastic seismic demand with the capacity of the coupled system. The seismic design action induces a ductility demand of 3.13 (Figure 10b) in the system.

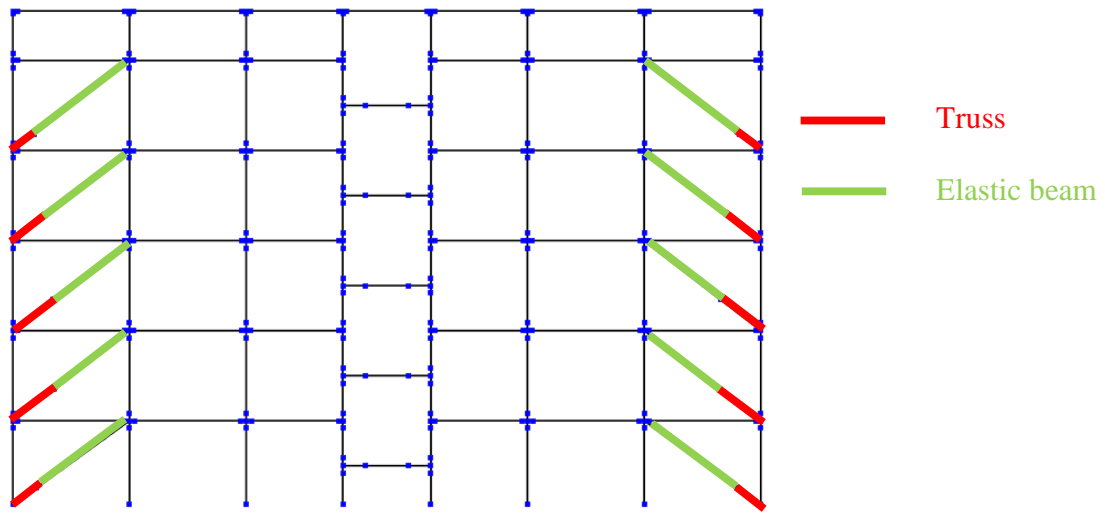

Figure 9. Modelling of the BRB by means of two elements (truss + elastic beam).
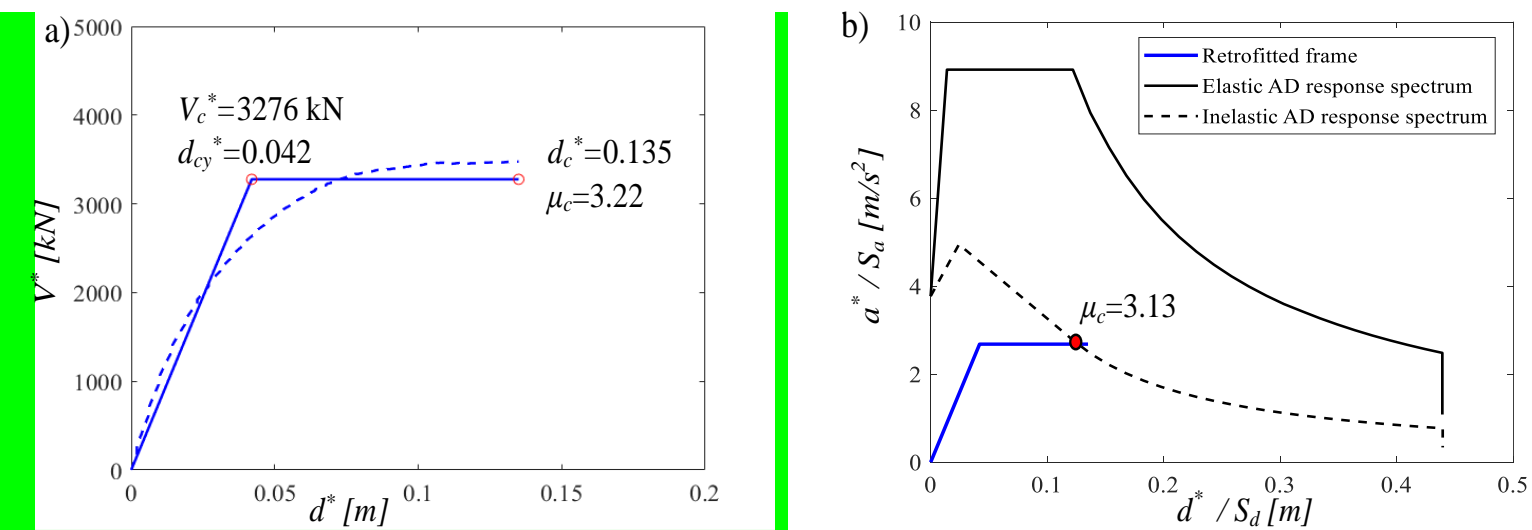

Figure 10. a) Capacity curve of the SDOF system equivalent to the retrofitted system and its bi-linearization and b) comparison between the seismic demand and capacity for the retrofitted frame. 
It is noteworthy that the design of the dissipative bracing system has been carried out disregarding the contribution of the infill walls. In order to evaluate the effect of the infill walls on the capacity of the system, a pushover analysis is performed on the models with and without BRBs and accounting for the contribution of the infills. Figure 11a compares the pushover curves for the bare frame with and without BRBs and for the infilled frame with and without BRBs. In general, the use of the BRBs results not only in an increased ductility capacity to the system, but also in a reduction of the softening following the attainment of the peak resistance. It can also be seen that the increase of peak base shear resistance due to the infill walls is of the order of $14 \%$ for the bare frame, and of $7 \%$ for the retrofitted frame. This small difference in both the cases is attributed to the presence of the weak infill walls. The increase of resistance for the case of the retrofitted frame is lower because the installation of the BRBs in the external spans of the frame requires replacing some infill walls with lighter ones that do not interact with the frame. Figure $11 \mathrm{~b}$ compares the seismic demand and capacity for the retrofitted model with infills. It can be seen that the performance point is characterized by a ductility demand for the coupled system $\mu_{c}=3.18$, which is only slightly higher than that observed for the model with no infills.
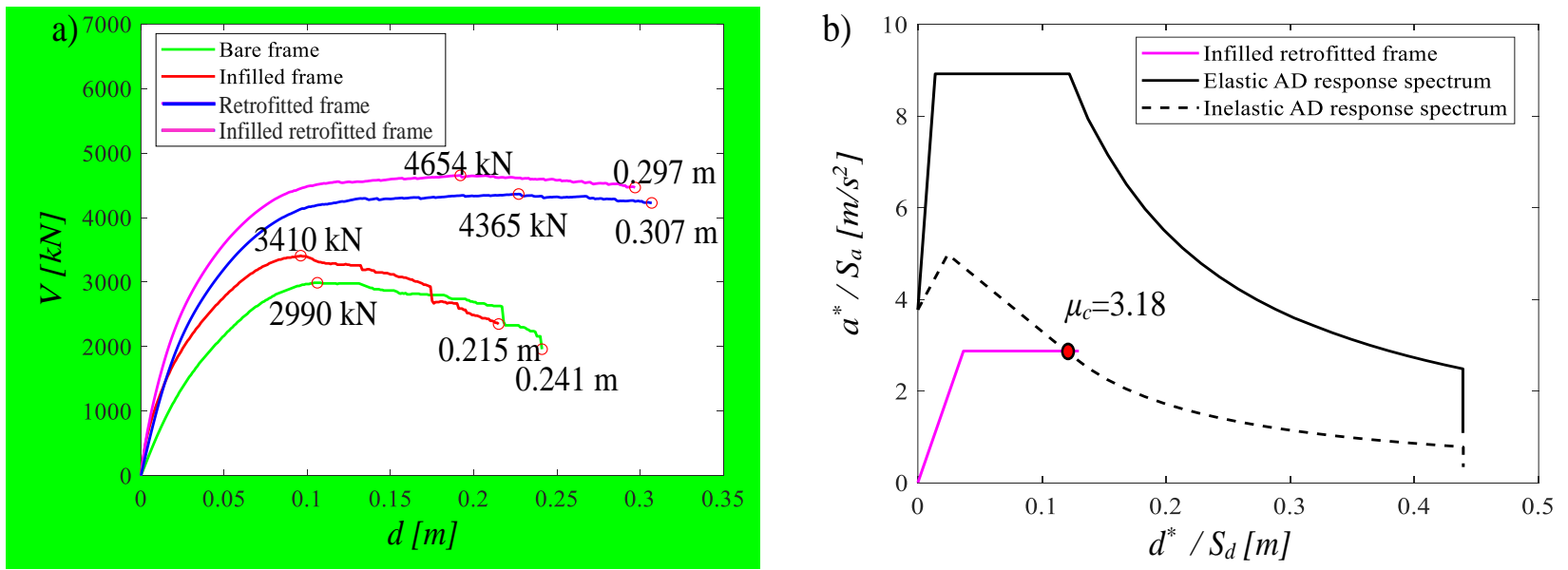

Figure 11. a) Capacity curves for the different models considered, and b) comparison between the seismic demand and capacity for the retrofitted frame with infill walls.

As already discussed above, the addition of the BRBs to the frame is expected to increase the axial deformations of the columns adjacent to them, and this in turn has an effect on the inter-storey drift response of the frame. As explained in [44], two different mechanisms contribute to the total IDR in frame panels: the first one is due to the shear flexibility of the story, and the second one is due to axial flexibility of the lower columns. This latter contribution results in a rigid body motion of the panel, which does not cause the panel to deflect and thus induces no damage. In order to shed light on this, the results of the pushover analysis of the various models have been post-processed in order to highlight the two contributions to the IDR for the panels belonging to the first span of the frame, where BRBs are inserted. Figure 12 shows the results of the analysis, in terms of total IDR and axial deformation contribution to the IDR, vs. the maximum IDR observe among the various floors. The total IDR for each storey is evaluated by dividing the relative horizontal floor displacements by the storey height, whereas reference can be made to [44] for the evaluation of the contribution from the axial column deformability. It can be observed that the contribution of the axial deformation of the columns to the total IDR is negligible for the models with no added BRBs (Figure 12a,c). This is expected, since the frame is only five storey high. On the other hand, in the models with the BRBs, the contribution of the axial deformation of the columns is not negligible, and can be of the order of $27 \%$ and $52 \%$ at the fourth and fifth storey. This is an important result considering that only the interstorey drift due to the shear flexibility of the panel is expected to cause damage to the frame [44]. It is also noteworthy that the BRB deformation is only related to the shear flexibility of the storey, and a rigid body motion of the panel result in no deformation of the BRBs (see also [45]). 
Since the shear contribution to the IDR changes from panel to panel, for simplicity only the total IDR is considered in the rest of the paper, as this results in a conservative estimate of the damage to the frame. This has no effect on the performance evaluation of the BRBs because their deformation is monitored directly in the analyses, without deriving it from the panel deflection.
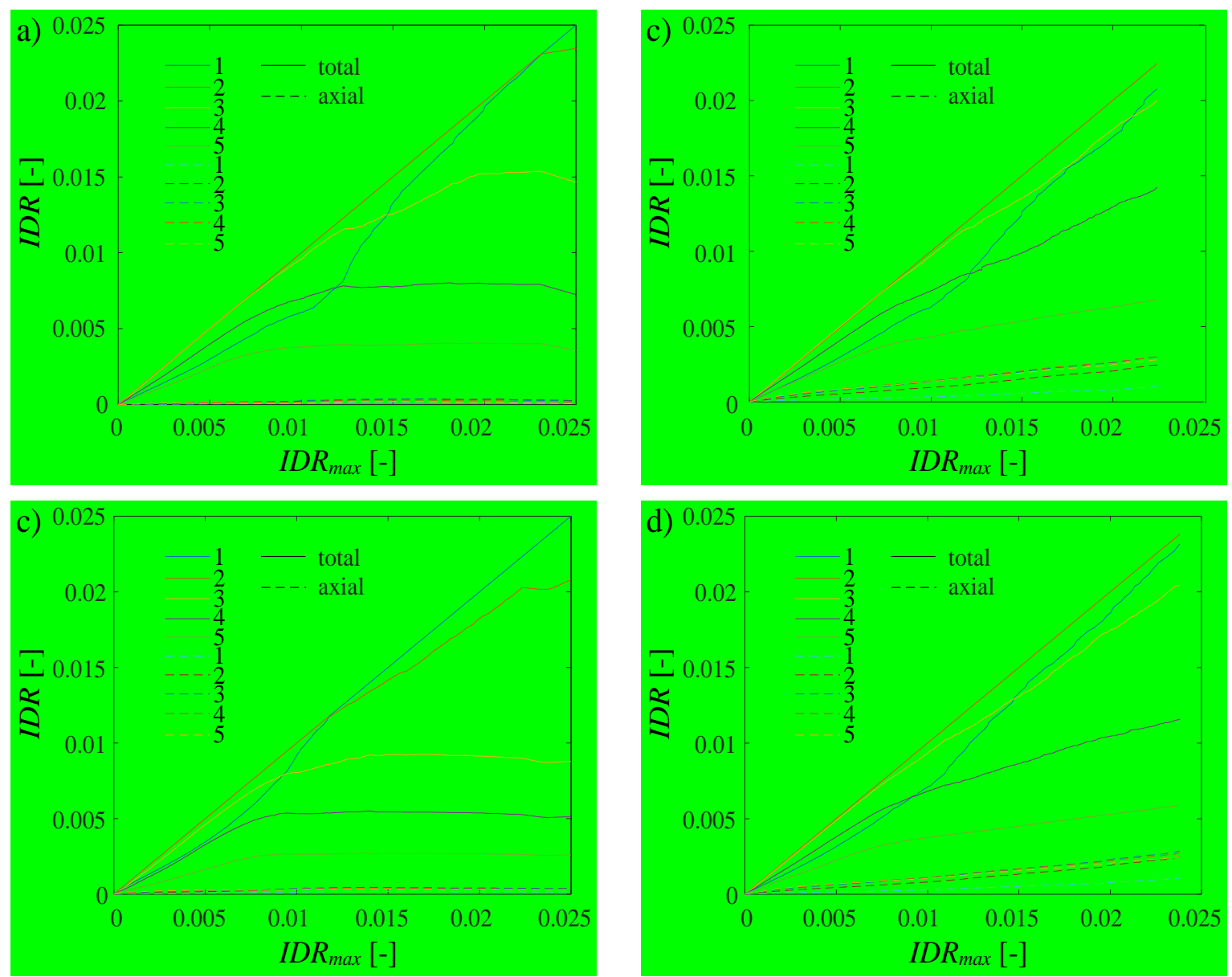

Figure 12. Total IDR and contribution of axial deformation of columns to the IDR at the various storeys of the first span

vs. maximum total IDR among the various storeys: Bare frame (a); Bare frame with BRBs (b); Infilled frame (c);

Infilled frame with BRBs (d). Continuous line for the total IDRs at the various storeys, dashed line for axial contribution.

\section{SEISMIC PERFORMANCE AND RETROFIT EFFECTIVENESS EVALUATION}

The seismic performance assessment of the system and the evaluation of the effectiveness of BRBs for the retrofit are based on the development and comparison of seismic demand hazard curves for different EDPs describing the seismic response of structural and non-structural components, as well as of the BRBs. Coherently with the performance-based earthquake engineering (PBEE) approach [45]-[49], the uncertainties related to the seismic input intensity are separated from those related to the characteristics of the record (i.e., record-to-record variability) by introducing an intensity measure (IM). In particular, the randomness in the seismic intensity is described by a hazard curve, whereas the record-to-record variability for a fixed intensity level is modelled by selecting a set of natural ground motion records characterized by a different duration and frequency content, scaled to the assumed intensity level [50].

It is worth to note that, in general, the IM's choice should be driven by criteria of efficiency, sufficiency and hazard computability [51]-[53]. In this study, the spectral acceleration, $S_{a}(\xi, T)$, at the fundamental period of the system, $T=2 \pi / \omega$ and for the damping ratio $\xi=5 \%$, is assumed as intensity measure. This is a structural dependent $I M$ that changes with the structural model. Table 5 
reports the periods of the four models considered, together with the corresponding $I M$ values at the life safety limit state (LFLS) and near collapse limit state (CLS).

Following the multi-stripe analysis [58], incremental dynamic analysis (IDA) [54] are carried out to investigate the response of the different systems for increasing intensity levels. The set of 30 ground motion records (record-to-record variability) employed in IDA are derived from 19 different seismic natural events (event-to-event variability), selected within the ground motion database of PEER (Pacific Earthquake Engineering Research Center) [55], of ITACA (Italian Accelerometric Archive) [56] and of ISESD (Internet-Site for European Strong-Motion Data) [57]. The characteristics of the selected ground motion records are reported in Table 6 . Their source-to-site distance, $R_{\mathrm{s}}$, is greater than $8.7 \mathrm{~km}$, and their moment magnitude, $\mathrm{M}$, is in the range between 6 and 7.6. Figure 13 shows the acceleration elastic response spectra of the unscaled records of Table 6.

The range of variation for the $I M$ has been selected in order to cover all the seismic intensities corresponding to all the limit states provided by [34] and illustrated in Table 5: in fact, being the highest seismic intensity related to NCLS equal to $0.959[\mathrm{~g}]$, the $I M$ has been selected to vary in the range $0 \mathrm{~g}-1 \mathrm{~g}$ with a step of $0.1 \mathrm{~g}$. This choice constitutes a good compromise between computational cost and accuracy of the estimates of the demand hazard curves [58].

Table 5. Periods of the four models.

\begin{tabular}{ccccc}
\hline & Bare frame & Retrofitted frame & Infilled frame & Inf. retrofitted frame \\
\hline $\boldsymbol{T}$ [s] & 0.850 & 0.637 & 0.836 & 0.632 \\
\hline $\boldsymbol{S}_{\boldsymbol{a}, L S L S}[\mathrm{~g}]$ & 0.787 & 0.909 & 0.799 & 0.909 \\
$\boldsymbol{S}_{a, N C L S}[\mathrm{~g}]$ & 0.851 & 0.959 & 0.865 & 0.959 \\
\hline
\end{tabular}

Table 6. Selected ground motions for the time history analyses.

\begin{tabular}{|c|c|c|c|c|c|c|c|c|}
\hline$\#$ & Year & Earthquake Name & Recording Station Name & $V_{s 30}[\mathrm{~m} / \mathrm{s}]$ & Fault Type & $\mathbf{M}[-]$ & $\mathbf{R}_{\mathrm{s}}[\mathbf{k m}]$ & PGA [g] \\
\hline 1 & 1994 & Northridge & Beverly Hills - Mulhol & 356 & Thrust & 6.7 & 13.3 & 0.52 \\
\hline 2 & 1994 & Northridge & Canyon Country-WLC & 309 & Thrust & 6.7 & 26.5 & 0.48 \\
\hline 3 & 1994 & Northridge & LA-Hollywood Stor & 316 & Thrust & 6.7 & 22.9 & 0.36 \\
\hline 4 & 1999 & Duzce, Turkey & Bolu & 326 & Strike-slip & 7.1 & 41.3 & 0.82 \\
\hline 5 & 1999 & Hector Mine & Hector & 685 & Strike-slip & 7.1 & 26.5 & 0.34 \\
\hline 6 & 1979 & Imperial Valley & Delta & 275 & Strike-slip & 6.5 & 33.7 & 0.35 \\
\hline 7 & 1979 & Imperial Valley & El Centro Array \#11 & 196 & Strike-slip & 6.5 & 29.4 & 0.38 \\
\hline 8 & 1995 & Kobe, Japan & Nishi-Akashi & 609 & Strike-slip & 6.9 & 8.7 & 0.51 \\
\hline 9 & 1995 & Kobe, Japan & Shin-Osaka & 256 & Strike-slip & 6.9 & 46.0 & 0.24 \\
\hline 10 & 1999 & Kocaeli, Turkey & Duzce & 276 & Strike-slip & 7.5 & 98.2 & 0.36 \\
\hline 11 & 1999 & Kocaeli, Turkey & Arcelik & 523 & Strike-slip & 7.5 & 53.7 & 0.22 \\
\hline 12 & 1992 & Landers & Yermo Fire Station & 354 & Strike-slip & 7.3 & 86.0 & 0.24 \\
\hline 13 & 1992 & Landers & Coolwater & 271 & Strike-slip & 7.3 & 82.1 & 0.42 \\
\hline 14 & 1989 & Loma Prieta & Capitola & 289 & Strike-slip & 6.9 & 9.8 & 0.53 \\
\hline 15 & 1989 & Loma Prieta & Gilroy Array \#3 & 350 & Strike-slip & 6.9 & 31.4 & 0.56 \\
\hline 16 & 1990 & Manjil, Iran & Abbar & 724 & Strike-slip & 7.4 & 40.4 & 0.51 \\
\hline 17 & 1987 & Superstition Hills & El Centro Imp. Co. & 192 & Strike-slip & 6.5 & 35.8 & 0.36 \\
\hline 18 & 1987 & Superstition Hills & Poe Road (temp) & 208 & Strike-slip & 6.5 & 11.2 & 0.45 \\
\hline 19 & 1987 & Superstition Hills & Westmorland Fire Stat. & 194 & Strike Slip & 6.5 & 15.1 & 0.21 \\
\hline 20 & 1992 & Cape Mendocino & Rio Dell Overpass & 312 & Thrust & 7.0 & 22.7 & 0.55 \\
\hline 21 & 1999 & Chi-Chi, Taiwan & CHY101 & 259 & Thrust & 7.6 & 32 & 0.44 \\
\hline 22 & 1999 & Chi-Chi, Taiwan & TCU045 & 705 & Thrust & 7.6 & 77.5 & 0.51 \\
\hline 23 & 1971 & San Fernando & LA - Hollywood Stor & 316 & Thrust & 6.6 & 39.5 & 0.21 \\
\hline 24 & 1976 & Friuli, Italy & Tolmezzo & 425 & Thrust & 6.5 & 20.2 & 0.35 \\
\hline 25 & 1980 & Irpinia & Bisaccia & 496 & & 6.9 & 21.3 & 0.94 \\
\hline 26 & 1979 & Montenegro & ST64 & 1083 & Thrust & 6.9 & 21.0 & 0.18 \\
\hline 27 & 1997 & Umbria Marche & ST238 & $\mathrm{n} / \mathrm{a}$ & Normal & 6.0 & 21.5 & 0.19 \\
\hline
\end{tabular}




\begin{tabular}{ccccccccc}
\hline 28 & 2000 & South Iceland & ST2487 & n/a & Strike Slip & 6.5 & 13 & 0.16 \\
\hline 29 & 2000 & South Iceland (a.s.) & ST2557 & n/a & Strike Slip & 6.4 & 15.0 & 0.13 \\
\hline 30 & 2003 & Bingol & ST539 & 806 & Strike Slip & 6.3 & 14.0 & 0.30 \\
\hline
\end{tabular}

The EDPs considered for monitoring the seismic response are the peak values, among the various storeys, of the interstorey drift ratio (IDR), the residual interstorey drift (RIDR), the absolute acceleration (ACC) and the maximum ductility (MD) and cumulative plastic ductility (CPD) in the BRBs. This latter is defined as the summation of all plastic displacements in the BRB, normalized by the yield displacement (see e.g. [27]).

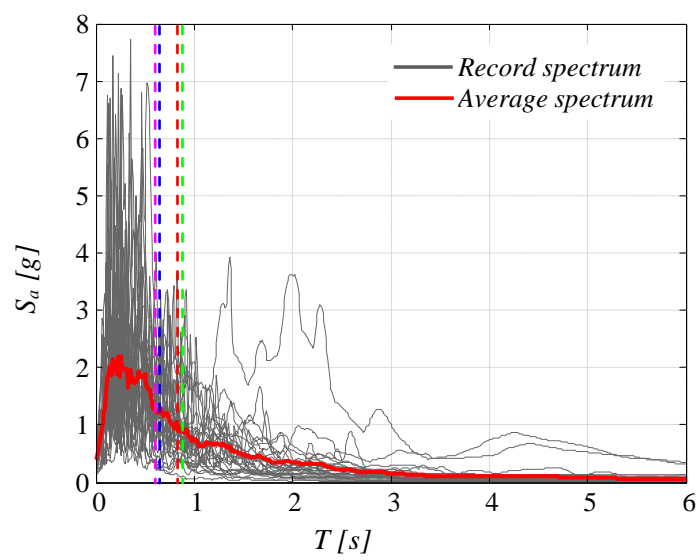

Figure 13. Acceleration elastic response spectra for the seismic records. The dashed lines indicate the structural periods of the various models.

It is noteworthy that for high $I M$ values, some convergence issues arise due to the failure of some fibers in critical sections and nonlinear geometrical behaviour of the model. Thus, the results reported in the figures below (Figures 14-16) refer only to the numerically-converging dynamic analysis points, which are reported in Table 7. Furthermore, the shear demand on the frame members and the diagonal stresses in the beam-column joints are also important response parameters that should be monitored. However, it is assumed that local strengthening of the critical elements adjacent to the BRBs is undertaken to avoid failure. Nevertheless, some checks were carried out on selected elements and no failure was observed up to high seismic intensity levels.

Table 7. Numerically-converging dynamic analysis points for each structural model and IM level.

\begin{tabular}{ccccccccccc}
\hline & $0.1[\mathrm{~g}]$ & $\mathbf{0 . 2}[\mathrm{g}]$ & $\mathbf{0 . 3}[\mathrm{g}]$ & $\mathbf{0 . 4}[\mathrm{g}]$ & $\mathbf{0 . 5}[\mathrm{g}]$ & $\mathbf{0 . 6}[\mathrm{g}]$ & $\mathbf{0 . 7}[\mathrm{g}]$ & $\mathbf{0 . 8}[\mathrm{g}]$ & $\mathbf{0 . 9}[\mathrm{g}]$ & $\mathbf{1}[\mathrm{g}]$ \\
\hline Bare frame & 30 & 30 & 30 & 28 & 26 & 25 & 22 & 20 & 18 & 15 \\
\hline Infilled frame & 30 & 30 & 30 & 30 & 28 & 28 & 26 & 24 & 21 & 20 \\
\hline Retrofitted frame & 30 & 30 & 30 & 30 & 30 & 30 & 30 & 28 & 26 & 21 \\
\hline $\begin{array}{c}\text { Infilled retrofitted } \\
\text { frame }\end{array}$ & 30 & 30 & 30 & 30 & 30 & 30 & 30 & 28 & 26 & 23 \\
\hline
\end{tabular}

Figure 14 shows the IDA curves in terms of IDR obtained for the various models considered. It can be observed in the plot that in the case of the bare frame, the IDR of $1.5 \%$ is reached at an $I M=0.3 \mathrm{~g}$ for the bare frame model, at $0.4 \mathrm{~g}$ for the infilled unretrofitted frame model, and at $0.7 \mathrm{~g}$ for both the retrofitted models. This results already shows the benefit of the use of the BRBs in terms of drift reduction, which is only partially impaired by the seismic demand increase due to period reduction (see Table 5). The IDA curves for the other EDPs of interest are not shown due to space constraint. 

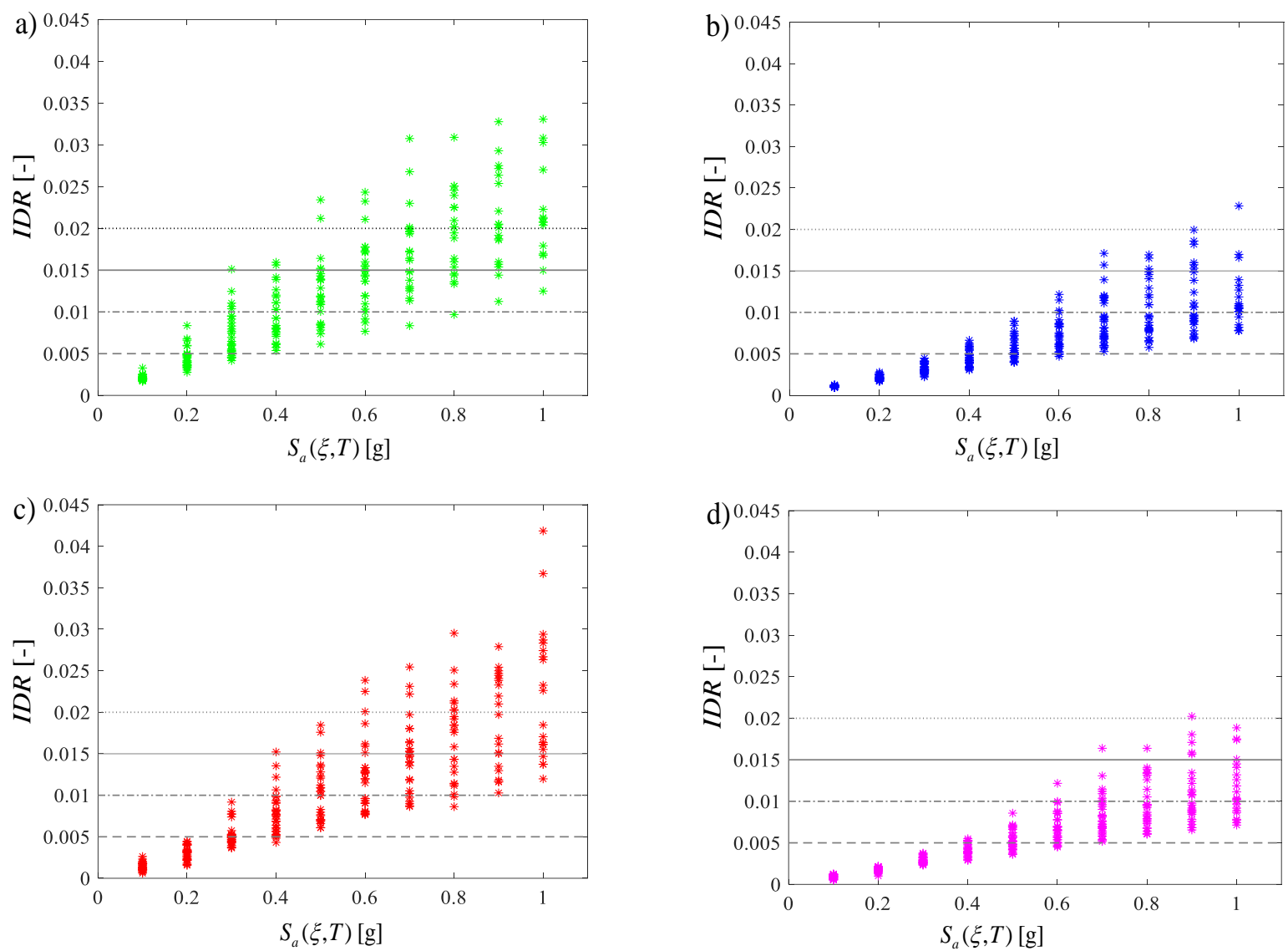

Figure 14. IDA results in terms of IDR: a) Bare frame; b) Bare frame with BRBs; c) Infilled bare frame; d) Infilled frame with BRBs.
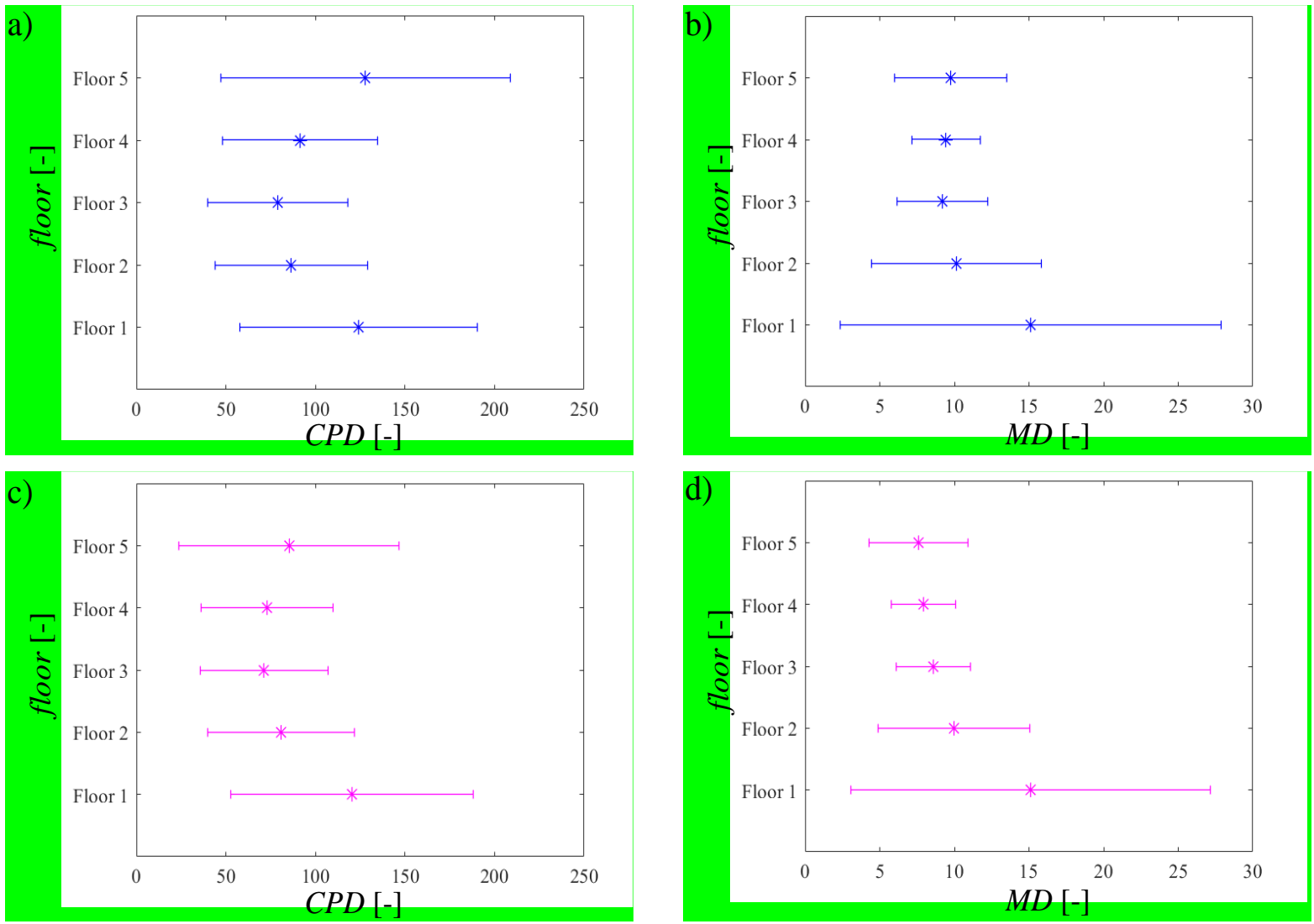

Figure 15. The statistics of the CPD and MD in height corresponding to the LSLS IM: CPD - Bare frame with BRBs a); MD - Bare frame with BRBs b); CPD - Infilled frame with BRBs c); MD - Infilled frame with BRBs c). 
Figure 15 illustrates the mean value of the demand and the mean value plus/minus the standard deviation of the CPD and of the MD for the BRB's at the various storeys, corresponding to the LSLS $I M$ level, for the two structural models equipped with BRBs. It can be observed that the objective of uniform distribution of plasticization sought in the design for the BRBs is achieved with a quite satisfactory performance. However, higher order modes affect the BRB deformation demand and result in a non-uniform distribution of the maximum ductility and cumulative ductility demand. Nevertheless,

Figure 16 shows the values of the residual inter-storey drift ratio (RIDRs) vs. the maximum values of the IDRs observed at each intensity level for each ground motion record considered. It is observed that the trend followed by the plots is the same for the various systems, i.e., the residual drifts are zero for very low values of the IDRs (less than $0.5 \%$ ) such that the system behaves elastically, and they increase more than linearly for increasing values of the IDR. In general, the RIDRs are more dispersed than the IDRs. Moreover, there is a quite good correlation between IDRs and RIDRs, except for the bare frame with infills (Figure 16c), characterized by a significant dispersion of the RIDRs. It is also worth to observe that the use of the BRBs results in an overall reduction of both the IDRs and of the RIDRs. This is due to the low ratio between the strength of the BRB and frame system (about $39 \%$ ), with the frame acting as a backup system and providing a restoring force mechanism [22]. The ratio of the RIDR to the IDR is always below the range of $40 \%-60 \%$ indicated by Sabelli et al. [21] for steel moment resisting frames equipped with BRBs, with the exception of the infilled bare frame (Figure 16c).

a)

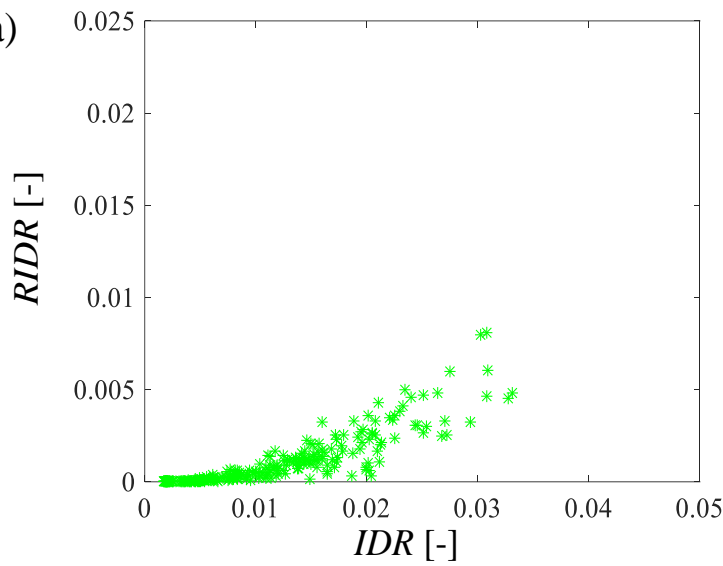

c)

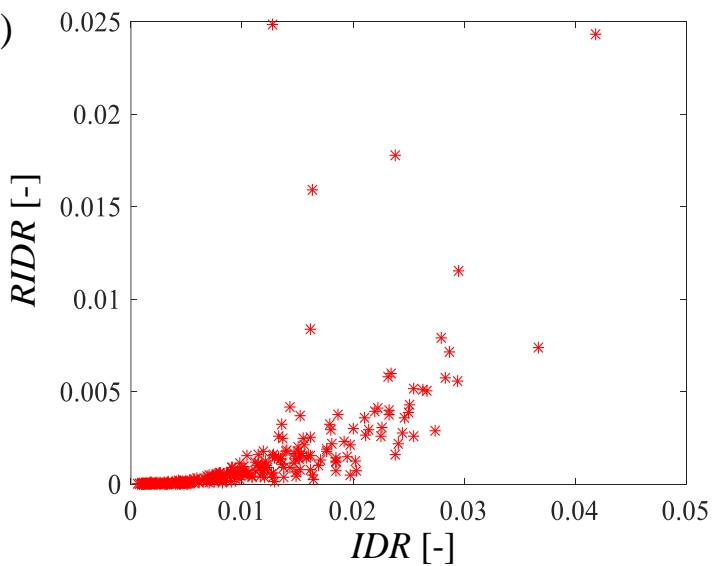

b)

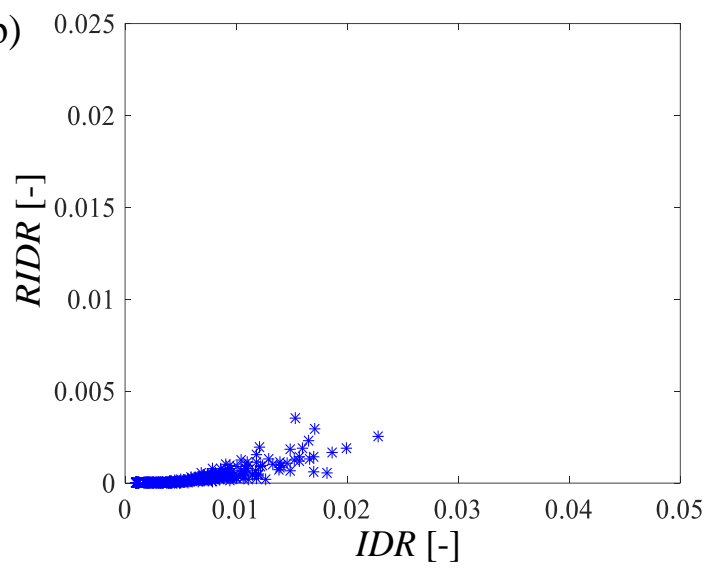

d)

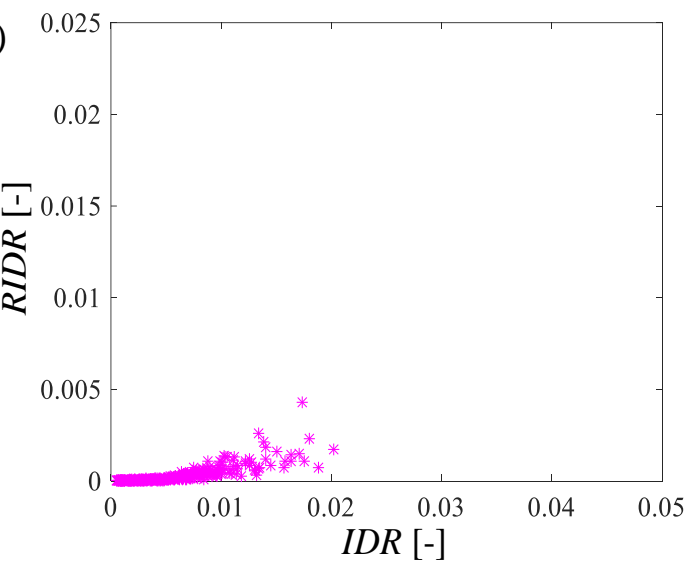

Figure 16. Residual interstory drift index vs. interstory drift index: Bare frame a); Bare frame with BRBs b); Infilled frame c); Infilled frame with BRBs d).

For each EDP considered, the conditional exceeding probability $G_{E D P \mid I M}(d \mid i m)$ is evaluated for the different models at the various IM levels considered. Both the collapse (and convergence) and not- 
collapse results are taken into account by applying the total probability theorem [59]-[61], according to the following expression:

$$
G_{E D P \mid M}(e d p \mid i m)=G_{E D P \mid I M}(e d p \mid i m, N C)(1-P[C \mid I M])+P[C \mid I M]
$$

where $G_{E D P \mid M}(e d p \mid i m, N C)$ is the probability of exceedance of the EDP conditional to the $I M$ and to not-collapse, the probability of collapse $P[C \mid I M]$ is evaluated numerically for each $I M$ level by dividing the number of analyses for which collapse occur by the total number of analyses.

Figure 17 shows the conditional exceedance curves for the IDRs, which are fitted by means of lognormal distributions. Five different demand thresholds are considered, namely $0.5 \%, 1 \%, 1.5 \%$, $2 \%$ and $2.5 \%$. These values correspond to increasing levels of seismic damage of the frame [45], [59],[60]. Obviously, the median value of the spectral acceleration corresponding to the threshold of $1.5 \%$ increases due to the retrofit and slightly decreases if the infill frames are considered in the models.

a)

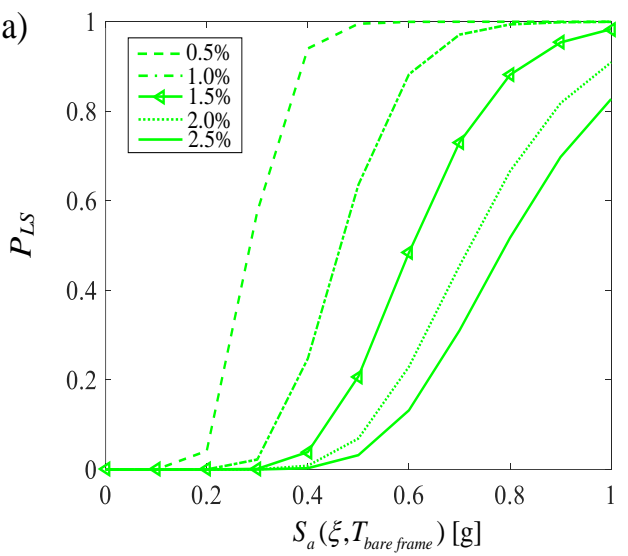

c)

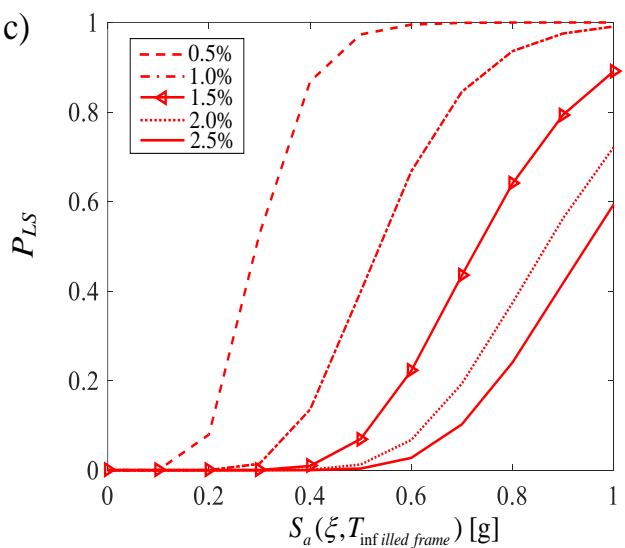

b)

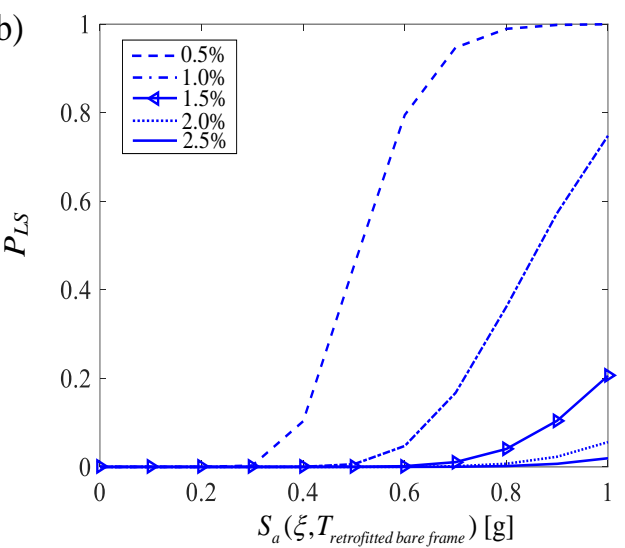

d)

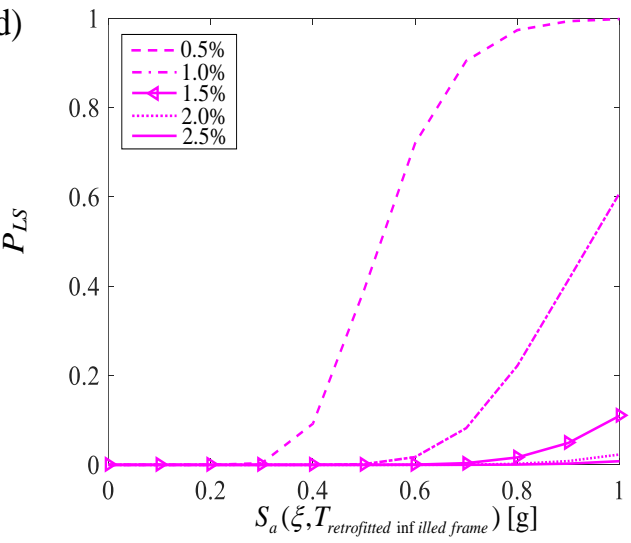

Figure 17. Conditional probability of exceedance vs. IM for the IDR: a) Bare frame; b) Bare frame with BRBs; c) Infilled frame; d) Infilled frame with BRBs.

Figure 18-Figure 21 illustrate the conditional exceedance curves for the other EDPs. In general, the exceeding probabilities decrease for increasing values of the threshold and increase for higher IM levels, as expected. The systems with added BRBs exhibit lower conditional probabilities compared to the ones without BRBs, for the same $I M$ and threshold levels, for all the monitored EDPs. If the presence of the infills is taken into account in the models, the exceedance probabilities reduce only slightly. It is also interesting to observe that the residual interstorey drifts exhibit a significant reduction due to the addition of the BRBs (Figure 16). Higher values of this ratio would have resulted in a global behaviour more affected by the low post-yield stiffness of the BRBs. 
Quite interestingly, also the probability of exceedance of the absolute accelerations slightly reduces due to the addition of the BRBs, whereas the infills have a minor effect on this probability. On the other hand, the presence of the infills leads to a more significant decrease of the maximum cumulative plastic deformations in the BRBs, as demonstrated by the lower values of the exceeding probabilities. It is noteworthy that the curves plotted in Figure 17-Figure 21 have been derived by considering different $I M S$ for each of the four models analysed. Thus, they could not be directly compared to each other. While in Freddi et al. [6] the concept of safety margin is used to compare fragility curves developed for a RC frame before and after the retrofit with BRBs, in this study seismic demand hazard curves, that are not conditional to the $I M$, are employed.
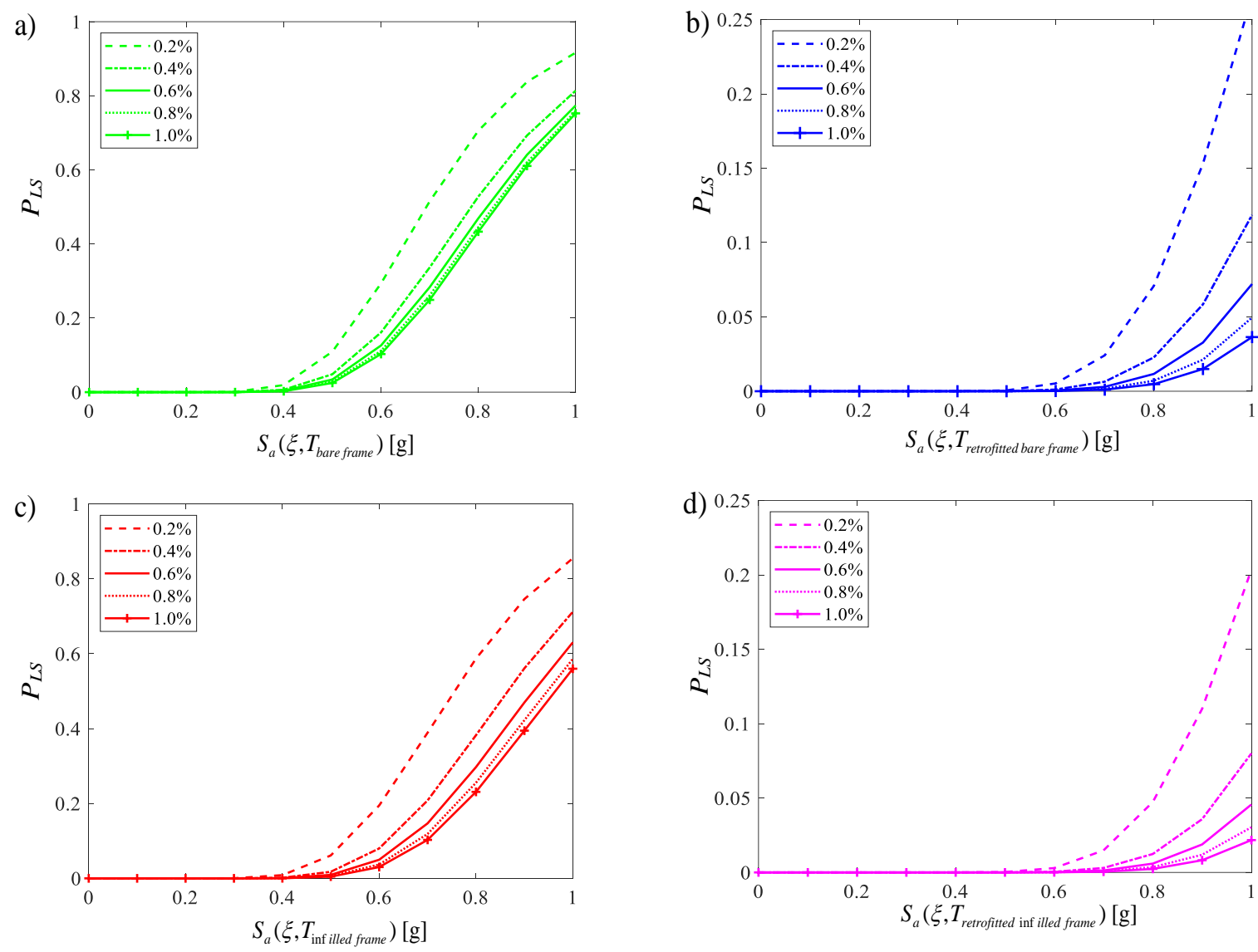

Figure 18. Conditional probability of exceedance vs. IM for the RIDR: a) Bare frame; b) Bare frame with BRBs; c) Infilled frame; d) Infilled frame with BRBs.

a)

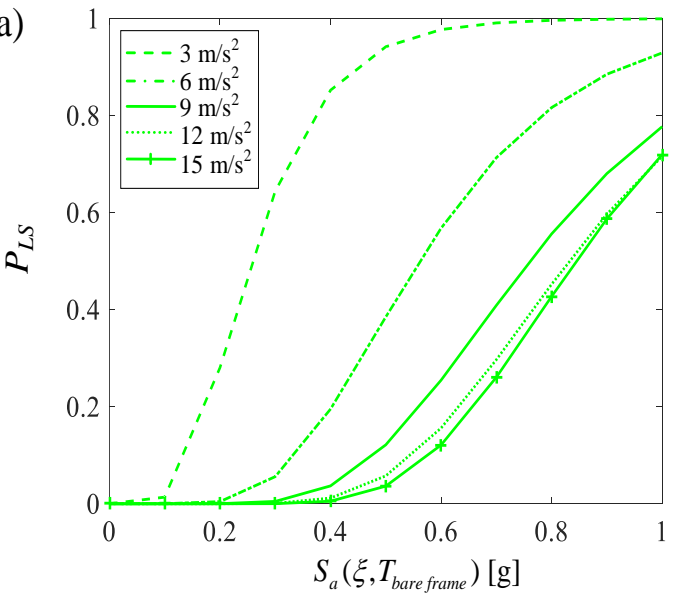

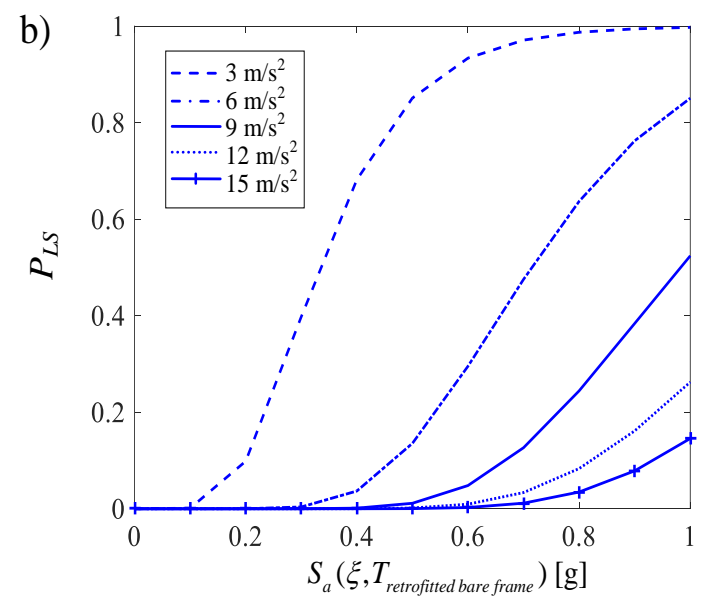


c)

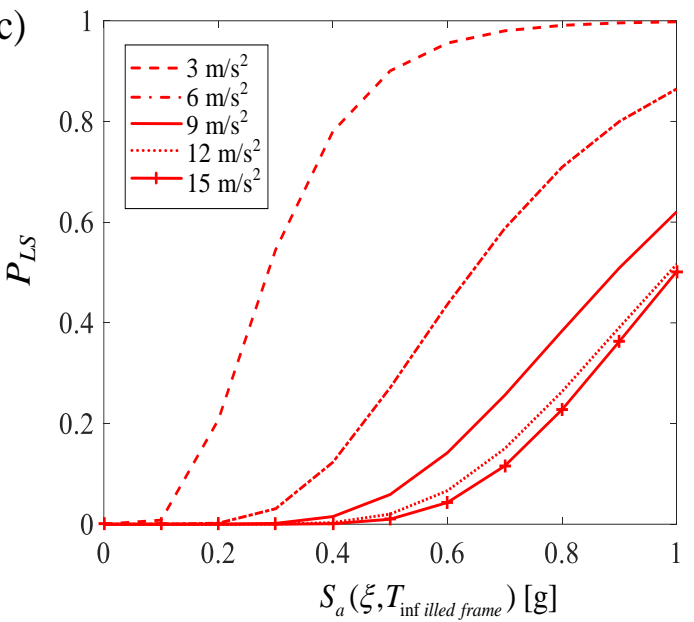

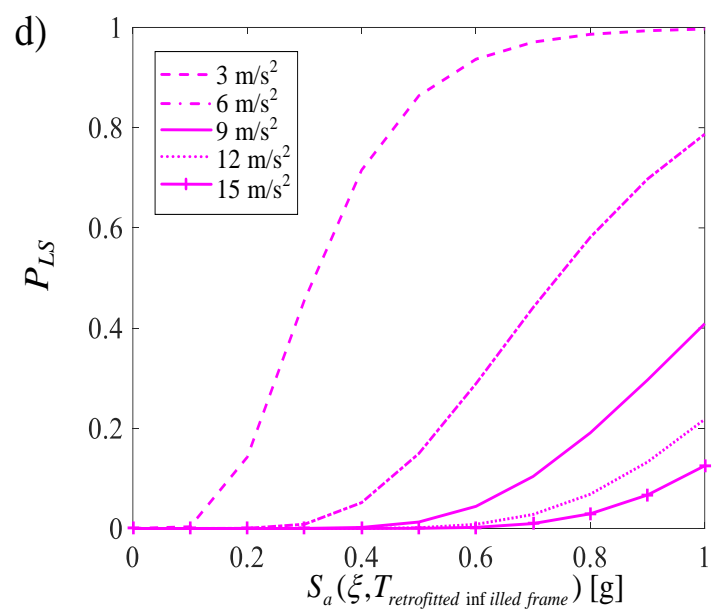

Figure 19. Conditional probability of exceedance vs. IM for the ACCs: a) Bare frame; b) Bare frame with BRBs; c) Infilled frame; d) Infilled frame with BRBs.

a)

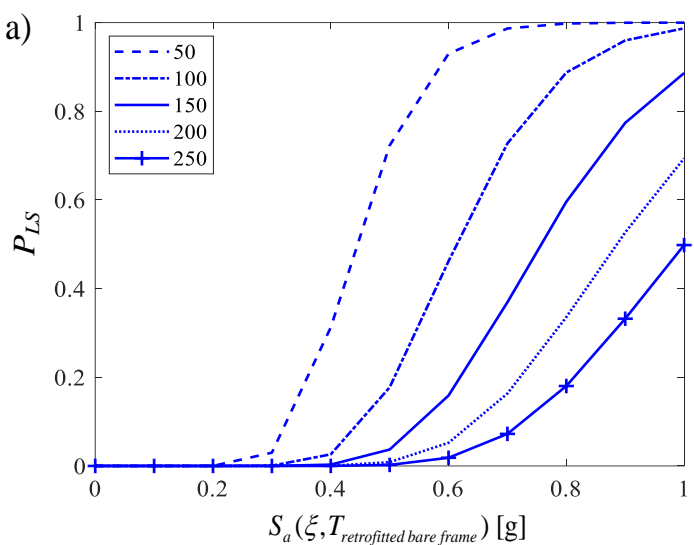

b)

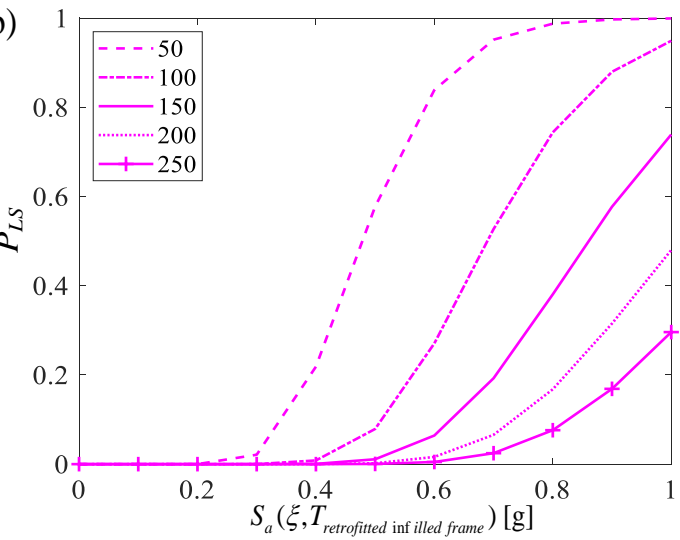

Figure 20. Conditional probability of exceedance vs. IM for the CPD: a) Bare frame with BRBs; b) Infilled frame with BRBs.

a)

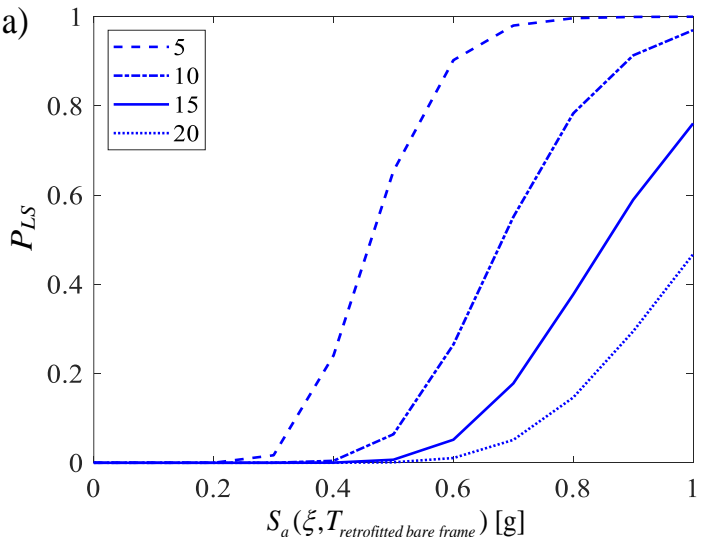

b)

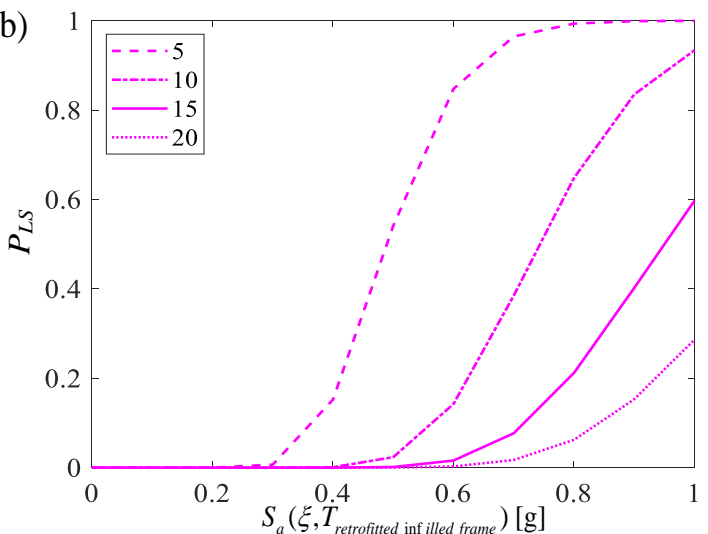

Figure 21. Conditional probability of exceedance vs. IM for the MD: a) Bare frame with BRBs; b) Infilled frame with BRBs.

\section{SEISMIC DEMAND HAZARD CURVES}

Figure 22 shows the seismic hazard curves, expressing the mean annual rate (MAF) of exceedance $\lambda$ of the various IMs considered in this study. These curves, plotted in semi-logarithmic scale, have been derived for the site in L'Aquila, where the structure is located, by following the procedure described in the Italian seismic code [34] and obtaining the necessary data from the National Institute 
of Geophysics and Volcanology (INGV) website [62]. It can be observed that for the same level of the MAF of exceedance, the spectral acceleration is higher for the retrofitted frame than for the unretrofitted frame, and higher for the infilled frame models than for the models without infills.
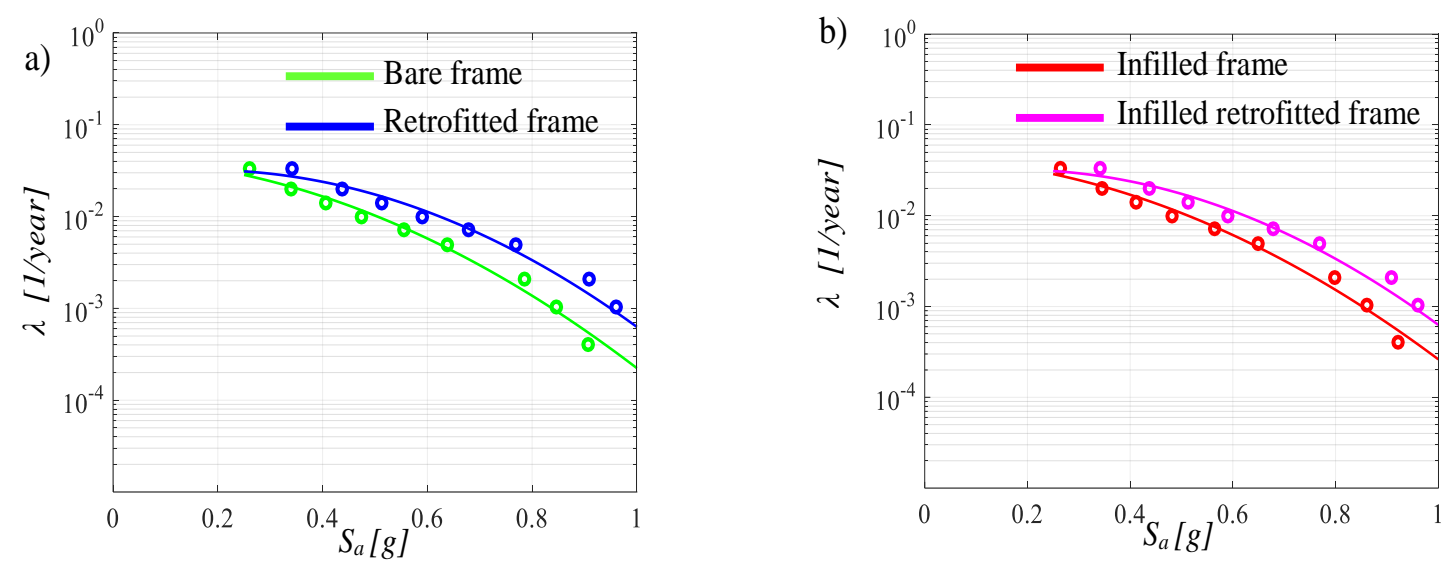

Figure 22. Seismic hazard curves for the unretrofitted frame and the frame retrofitted with BRBs obtained by neglecting the infill wall contribution a) and by considering the infill wall contribution b).

The seismic demand hazard curves for the various systems and EDPs of interest are obtained by convolution of the conditional probability of exceedance (Figure 17 to Figure 21) with the relevant seismic hazard curve (Figure 22). The demand hazard curve for the generic EDP can be estimated as follows:

$$
\lambda_{E D P}(e d p)=\int_{0}^{\infty} G_{E D P \mid I M}(e d p \mid i m)\left|\frac{d \lambda_{I M}(i m)}{d(i m)}\right| d(i m)
$$

where $d(\cdot)$ denotes the differential operator.

Figure 23 shows the demand hazard curves of the various EDPs of interest obtained for the four structural models considered. Table 8-Table 11 show the values of the MAF of exceedance for some values of these EDPs.

With regard to the IDR, it can be observed that the BRBs are effective to reduce the seismic demand to more acceptable values. In particular, the MAF of exceedance of the $0.5 \%$ threshold, commonly associated to onset of nonlinear behaviour of the frame, reduces from 0.01641 /year to 0.0249 1/year, whereas the MAF of exceedance of the $2 \%$ threshold, associated to significant damage to the frame, reduces from 0.00371 /year to 0.0001 1/year. Thus, the performance improvement is higher for high drift levels. It is also interesting to observe that the MAF of exceedance of the $1.5 \%$ limit, which is considered for the design of the BRBs, is equal to $6 \cdot 10^{-4} 1$ year for the case of the retrofitted frame. This value is lower than the MAF of exceedance of the design seismic input, which is $2.1 \cdot 10^{-3} 1 /$ year. The discrepancy may be due to the simplifying assumptions of the design procedure, particularly the fact that the isotropic hardening behavior of the BRBs is neglected when evaluating the pushover curve of the retrofitted frame. Nevertheless, the MAF of exceedance is higher than the reference MAF of collapse that is targeted by the risk-based design approaches in the US [63]. In Europe, lower values of the MAF of collapse are sought for new structures, (about $10^{-5}-10^{-6} 1 /$ year [60],[63].

Accounting for the presence of the infills results in further reductions of the IDR demand. A similar trend is observed for the RIDR, i.e., both the BRBs and the infills result in lower RIDR demands. The MAF of exceedance of the RIDR of $0.5 \%$, which is often considered as a limit beyond which the building is not repairable, is about $2.5 \cdot 10^{-3} 1$ year for the bare frame, and $2.5 \cdot 10^{-4} 1$ year for the frame with BRBs. Thus, the BRBs are also effective in reducing the residual drift. This is a very important result, showing that a proper design of the BRBs, such that the bracing system to frame strength ratio is low, avoids the problem of localization of plasticization deformations the BRBs are prone due to their low post-yield stiffness [64]. In fact, for low values of this ratio, the frame system acts as a 
backup system, providing a restoring force mechanism and preventing significant inelastic behavior at any storey.
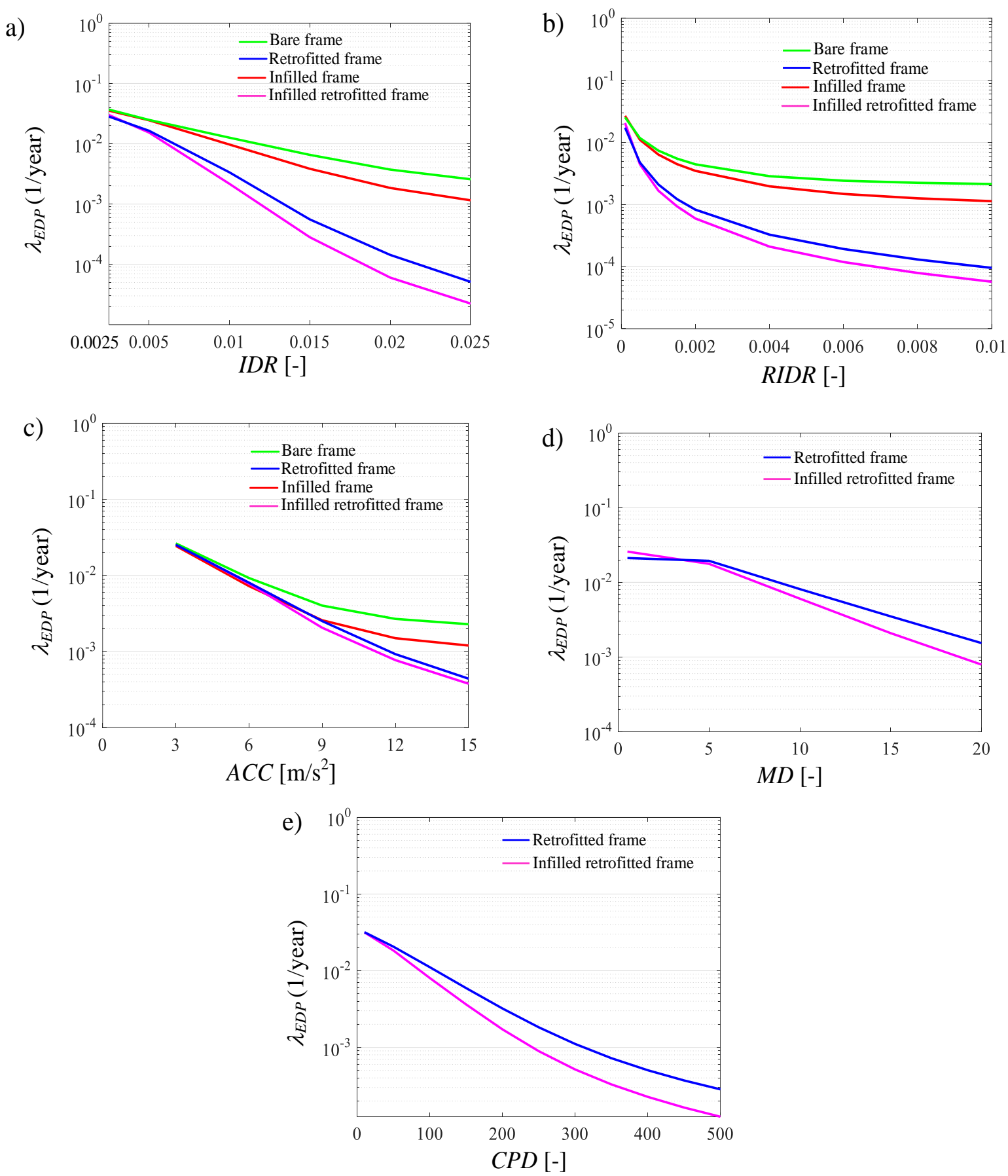

Figure 23. Demand hazard curves of the EDPs for the different structural models considered: IDR (a); RIDR (b); ACC (c); MD (d); CPD (e).

In Figure 23c, it is interesting to observe that the curve of the MAF of exceedance of the absolute accelerations is very similar for all the models for low acceleration values, below $9 \mathrm{~m} / \mathrm{s}^{2}$. This is because adding the BRBs and the infills to the frame results both in a decrease of period, which would increase the acceleration demand, but also in an increase of energy dissipation, which on the other hand reduces the acceleration demand. Thus, this type of retrofit is not very effective in improving the performance of acceleration-sensitive non-structural components. Some improvements in terms of acceleration demand reduction can be observed for acceleration value higher than $9 \mathrm{~m} / \mathrm{s}^{2}$. The infill walls have a negligible influence on the acceleration demand hazard curve. This is mainly because 
the increase of stiffness due to the infills, causing an increase of acceleration demand, is compensated by the reduction of acceleration demand due to the energy dissipation associated to their damage. Similar results have been observed in other studies (see e.g. [65],[66]).

Figure 23d shows the MAF of exceedance of the maximum ductility demand in the BRB device. The MAF of exceedance of the value $\mu_{0 c}=15$, which is considered in the design, is about $1.5 \cdot 10^{-3} 1 /$ year for the case of the frame with no infills, and about $8 \cdot 10^{-4} 1 /$ year for the case of the frame with infills. Thus, the probability that BRBs exceed their design ductility capacity is higher than the probability of the frame exceeding the design IDR level $\left(6 \cdot 10^{-4}\right.$ 1/year in the case of the frame with no infills, and to $2.5 \cdot 10^{-4}$ in the case of infilled frame). Nevertheless, the maximum ductility capacity of the BRBs is higher than the design value, and usually it is equal to 20 or more.

Finally, from Figure 23e, values of the CPD of 250 for the BRB devices are exceeded with a MAF of $1.8 \cdot 10^{-3} 1$ year for the case of the frame with no infills, and about $9 \cdot 10^{-4} 1$ year for the case of the frame with infills. Since the CPD capacity of BRBs is usually much higher, in the order of 350-400 for maximum ductility demand of the order of 15 [28],[29], the BRBs are expected to have a good safety margin against low cycle fatigue and exhibit a significant reserve capacity should aftershocks occur.

Table 8. Mean annual rate exceeding different values of the IDRs for the various structural models.

\begin{tabular}{ccccc}
\hline IDR & Bare frame & Retrofitted frame & Infilled frame & Inf. retrofitted frame \\
\hline 0.005 & 0.0249 & 0.0164 & 0.0245 & 0.0153 \\
\hline 0.01 & 0.0126 & 0.0034 & 0.0097 & 0.0022 \\
\hline 0.015 & 0.0065 & 0.0006 & 0.0038 & 0.0003 \\
\hline 0.02 & 0.0037 & 0.0001 & 0.0018 & 0.00006 \\
\hline 0.025 & 0.0026 & 0.00005 & 0.0012 & 0.00002 \\
\hline
\end{tabular}

Table 9. Mean annual rate exceeding different values of the RIDRs for the various structural models.

\begin{tabular}{ccccc}
\hline RIDR & Bare frame & Retrofitted frame & Infilled frame & Inf. retrofitted frame \\
\hline 0.0005 & 0.0118 & 0.0048 & 0.0111 & 0.0044 \\
\hline 0.001 & 0.0074 & 0.0021 & 0.0064 & 0.0017 \\
\hline 0.002 & 0.0044 & 0.0008 & 0.0035 & 0.0006 \\
\hline 0.004 & 0.0029 & 0.0003 & 0.0020 & 0.0002 \\
\hline 0.005 & 0.0026 & 0.00024 & 0.0017 & 0.00015 \\
\hline 0.006 & 0.0024 & 0.00019 & 0.0015 & 0.00012 \\
\hline 0.01 & 0.0021 & 0.00009 & 0.0011 & 0.00006 \\
\hline
\end{tabular}

Table 10. Mean annual rate exceeding different values of the ACCs for the various structural models.

\begin{tabular}{ccccc}
\hline Acc $\left[\mathbf{m} / \mathbf{s}^{\mathbf{2}}\right]$ & Bare frame & Retrofitted frame & Infilled frame & Inf. retrofitted frame \\
\hline 3 & 0.0263 & 0.0253 & 0.0244 & 0.0258 \\
\hline 6 & 0.0092 & 0.0080 & 0.0072 & 0.0078 \\
\hline 9 & 0.0040 & 0.0025 & 0.0026 & 0.0021 \\
\hline 12 & 0.0027 & 0.0009 & 0.0015 & 0.0008 \\
\hline 15 & 0.0023 & 0.0004 & 0.0012 & 0.0004 \\
\hline
\end{tabular}


Table 11. Mean annual rate exceeding different values of the MD and of the CPD for the various structural models.

\begin{tabular}{ccc|ccc}
\hline $\begin{array}{c}\text { BRBs, } \\
\text { ductility } \\
{[-]}\end{array}$ & $\begin{array}{c}\text { Retrofitted } \\
\text { frame }\end{array}$ & $\begin{array}{c}\text { Inf. retrofitted } \\
\text { frame }\end{array}$ & $\begin{array}{c}\text { BRBs' } \\
\text { CPD } \\
{[-]}\end{array}$ & $\begin{array}{c}\text { Retrofitted } \\
\text { frame }\end{array}$ & $\begin{array}{c}\text { Inf. retrofitted } \\
\text { frame }\end{array}$ \\
\hline 0.5 & 0.0212 & 0.0258 & 50 & 0.0205 & 0.0183 \\
\hline 5 & 0.0194 & 0.0177 & 100 & 0.0111 & 0.0080 \\
\hline 10 & 0.0081 & 0.0060 & 200 & 0.0032 & 0.0017 \\
\hline 15 & 0.0035 & 0.0021 & 250 & 0.0018 & 0.0009 \\
\hline 20 & 0.0015 & 0.0008 & 500 & 0.0003 & 0.00012 \\
\hline
\end{tabular}

\section{CONCLUSIONS}

In this work, a performance-based approach is employed to evaluate the efficiency of the retrofitting of an existing RC building with buckling restrained braces (BRBs), by also considering the influence of the infill walls on the performance assessment. In particular, an existing reinforced concrete building located in L'Aquila is used as case study. An advanced non-linear model of the existing RC building, accounting also for the effect of the infill walls, is defined in OpenSees. The model is threedimensional, therefore, able to account for the actual distribution of masses, including those of the infill partitions, but the evaluation of the seismic performance of both the building in its original state and after the retrofit, has been conducted only regarding in the weak direction of the building, the $\mathrm{X}$ one, where the seismic excitation has been applied. The braces have been designed in accordance to a widely employed procedure based on pushover analyses. Specifically, the bracing system is designed to obtain a retrofitted bare structure that is able to withstand the seismic demand associated to the life safety limit state design spectrum (return period of 475 years) experiencing a maximum absolute interstorey drift index of $1.5 \%$. Successively, the seismic performance of the retrofitted bare/infilled building is evaluated by performing both non-linear static analyses and incremental dynamic analyses under a set of real ground motion records scaled to increasing seismic intensity levels. Seismic demand hazard curves are estimated for the interstorey drifts and other engineering demand parameters. The spectral acceleration at the fundamental period of the bare or infilled structure for a damping factor of $5 \%$ is used as intensity measure.

Based on the study results, the following conclusions can be drawn:

- Adding a relatively light BRB brace system to the existing frame results in notable performance improvements. In fact the use of the BRBs provides not only an increased ductility capacity to the system, but also a reduction of the softening behavior following the attainment of the peak resistance, as shown by the capacity curves of the analysed models. The benefit in terms drift reduction due to the use of BRBs are also evident by observing the demand hazard curves for the IDRs. The MAF of exceedance of the $1.5 \%$ limit, which is considered for the design of the BRBs, is equal to $6 \cdot 10^{-4} 1$ year for the case of the retrofitted frame with no infills, and it is about $1 / 10$ of the corresponding MAF level for the case of the bare frame with no BRBs.

- For what concerns the residual drifts, it can be seen that for values of IDR $<0.5 \%$, corresponding to the onset of inelastic behaviour of the building, the RIDR are zero, while they increase more than linearly for higher values of IDR. In general, the use of the BRBs results in an overall reduction of the RIDRs. This is due to the low ratio between the strength of the BRB and that of the frame system, which acts as a backup system and provides a restoring force mechanism. The risk of having excessive residual drifts is significantly lower than the risk of exceeding critical IDR levels during the earthquake action.

- The retrofit with BRBs does not reduce significantly the risk of exceeding absolute acceleration demands less than $9 \mathrm{~m} / \mathrm{s}^{2}$, but it is more effective for higher acceleration levels. Thus, alternative 
retrofit measures may have to be employed if the seismic performance of acceleration-sensitive non-structural components has to be minimized.

- The performance of the BRBs is quite satisfactory in terms of exceedance of the design value of the maximum ductility capacity, and the MAF of exceeding critical levels of the cumulative ductility capacity is very low. This means that the BRBs exhibit a significant reserve capacity even under rare earthquake events.

- For the case study analysed, accounting for the presence of the infills provides some improvement in the performance of both the unretrofitted and retrofitted system. However, this improvement is not very significant, due to the low contribution of the infills to the stiffness and strength of the system. Moreover, disregarding the infills in the BRBs design does not impair the efficiency of the retrofit intervention.

\section{REFERENCES}

[1] Soong T.T., Dargush G.F. Passive Energy Dissipation Systems in Structural Engineering. Wiley \& Sons, 1997.

[2] Soong T.T., Constantinou M.C. Passive and Active Structural Vibration Control in Civil Engineering. Springer-Verlag: Wien-New York, 1994.

[3] Castaldo P., De Iuliis M. Optimal integrated seismic design of structural and viscoelastic bracing-damper systems. Earthquake Engineering and Structural Dynamics. 2014; 43(12): 1809-1827.

[4] Soong T.T., Spencer B.F. Jr. Supplemental energy dissipation: state of the art and state of the practice. Engineering Structures. 2002; 24(3): 243-259.

[5] Di Sarno L., Manfredi G. Seismic retrofitting of existing RC frames with buckling restrained braces. ATC \& SEI 2009 Conference on Improving the Seismic Performance of Existing Buildings and Other Structures.

[6] Freddi F., Tubaldi E., Ragni L., Dall'Asta A. Probabilistic performance assessment of lowductility reinforced concrete frames retrofitted with dissipative braces. Earthquake Engineering \& Structural Dynamics. 2013; 42(7): 993-1011.

[7] Sadeghi S., Rofooei F.R. Improving the seismic performance of diagrid structures using buckling restrained braces. Journal of Construction Steel Research, 2020, https://doi.org/10.1016/j.jcsr.2019.105905.

[8] Brown A.P., Aiken I.D., Jafarzadeh F.J. Buckling Restrained Braces Provide the Key to the Seismic Retrofit of the Wallace F. Bennett Federal Building. Modern Steel construction, AISC, 2001.

[9] Tremblay R., Degrange G., Blouin J. Seismic rehabilitation of a four-storey building with a stiffened bracing system. Proceedings of the $8^{\text {th }}$ Canadian Conference on Earthquake Engineering, Vancouver, Canada 1999.

[10] Di Sarno L, Elnashai AS. Bracing systems for seismic retrofitting of steel frames. J Construct Steel Res 2009;65(2):452-65. http://dx.doi.org/10.1016/j.jcsr.2008.02.013.

[11] De Domenico, D., Impollonia, N., and Ricciardi, G. (2019a). Seismic retrofitting of confined masonry-RC buildings: The case study of the university hall of residence in Messina, Italy. Ingegneria Sismica 36, 54-85.

[12] Bozorgnia Y., Bertero V.V. Earthquake Engineering: From Engineering Seismology to Performance-Based Engineering. ICC-CRC Press, Boca Raton, Florida, USA 2004.

[13] Watanabe A., Hitomi Y., Saeki E., Wada A., Fujimoto M. Properties of Brace Eneased in Concrete-Filled Steel Tube. Proceedings of the $9^{\text {th }}$ World Conference on Earthquake Engineering, Tokyo-Kyoto, Japan, 1988.

[14] Iwata M., Kato T., Wada A. Buckling-restrained braces as hysteretic dampers. Proc. STESSA 2000 Conf., 33-38, Montreal, Canada, August 2000.

[15] Black C., Makris N., Aiken I. Component Testing, Stability Analysis and Characterization of 
Buckling-Restrained Unbonded Braces. Report No. PEER 2002/08, Univ. of California, Berkeley, CA, 2002.

[16] Dall'Asta A., Ragni L., Tubaldi E., Freddi F. Design methods for existing r.c. frames equipped with elasto-plastic or viscoelastic dissipative braces. Conference: XIII National Conference ANIDIS: L'Ingegneria sismica in Italia, 2009.

[17] Di Sarno L., Manfredi G. Seismic retrofitting with buckling restrained braces: Application to an existing non-ductile RC framed building. Soil Dynamics and Earthquake Engineering. 2010; 30(11): 1279-1297.

[18] Sutcu F., Takeuchi T., Matsui, R. Seismic retrofit design method for RC buildings using buckling-restrained braces and steel frames. Journal of Constructional Steel Research. 2014; 101: 304-313.

[19] Güneyisi EM. Seismic reliability of steel moment resisting framed buildings retrofitted with buckling restrained braces. Earthquake Engineering and Structural Dynamics. 2012; 41(5): 853-874.

[20] Zahrai S. M., Moradi A., Moradi M. Using friction dampers in retrofitting a steel structure with masonry infill panels. Steel and Composite Structures. 2015; 19(2): 309-325.

[21] Sabelli R, Mahin SA, Chang C. Seismic demands on steel braced-frame buildings with buckling-restrained braces. Engineering Structures. 2003; 25: 655-666.

[22] Erochko J., Christopoulos C., Tremblay R., and Choi, H. Residual drift response of SMRFs and BRB frames in steel buildings designed according to ASCE 7-05. Journal of Structural Engineering. 2011; 137(5): 589-599.

[23] Kiggins S., Uang, C. M. Reducing residual interstory drift of buckling-restrained braced frames as a dual system. Engineering Structures. 2006; 28(11): 1525-1532.

[24] Uang C.M., Nakashima M., Tsai K.C. Research and application of buckling restrained braced frames. International Journal of Steel Structures. 2004; 4(4):301-13.

[25] Xie Q. State of the art of buckling-restrained braces in Asia. Journal of constructional steel research. 2005; 61(6): 727-48.

[26] Takeuchi T., Ida M., Yamada S., Suzuki K. Estimation of cumulative deformation capacity of buckling restrained braces. Journal of Structural Engineering. 2008; 134(5): 822-31.

[27] Andrews B.M., Fahnestock L.A. Song J. Ductility capacity models for buckling restrained braces. Journal of Constructional Steel Research. 2009; 65(8-9): 1712-20.

[28] Fahnestock L. A., Ricles J. M., Sause R. Experimental evaluation of a large scale bucklingrestrained braced frame. Journal of Structural Engineering. 2007; 133(9): 12051214.

[29] Merritt S., Uang C. M., Benzoni G. Subassemblage testing of Star Seismic buckling-restrained braces. Structural Systems Research Project, Rep. No. TR-2003/04, Univ. of California at San Diego, San Diego, 2003.

[30] Zona A., Dall'Asta A. Elastoplastic model for steel buckling-restrained braces. Journal of Constructional Steel Research. 2012; 68(1): 118-125.

[31] Gu, Q., Zona, A., Peng, Y., \& Dall'Asta, A. (2014). Effect of buckling-restrained brace model parameters on seismic structural response. Journal of Constructional Steel Research, 98: 100113.

[32] McKenna F., Fenves G.L., Scott M.H. OpenSees: Open system for earthquake engineering simulation. Pacific Earthquake Engineering Research Center, University of California, Berkeley, CA, 2006.

[33] Fajfar P. A nonlinear analysis method for performance-based seismic design. Earthquake Spectra. 2000; 16(3): 573-592.

[34] Ministero delle Infrastrutture e dei Trasporti (2018). Aggiornamento delle "Norme tecniche per le costruzioni" (NTC 2018). Gazzetta Ufficiale 20/02/2017, n. 42 - Suppl. Ord. n. 8.

[35] The Concrete Society Technical Report 11 - TR 11 Concrete core testing for strength 1976, amended 1987

[36] Mander J. B., Priestley M. J., Park R. Theoretical Stress-Strain Model for Confined Concrete. 
Journal of Structural Engineering. 1988; 114(8).

[37] European committee for standardization (2004). Eurocode 2: Design of concrete structures. Part 1.1: General rules and rules for buildings. Brussels, Belgium.

[38] Decanini L., Mollaioli F., Mura A., Saragoni R. (2004). Seismic performance of masonry infilled $\mathrm{r} / \mathrm{c}$ frames. Proceeding of the $13^{\text {th }}$ World Conference on Earthquake Engineering, Vancouver, Canada.

[39] Scott MH, Fenves GL. Plastic hinge integration methods for force-based beam-column elements. Journal of Structural Engineering. 2006; 132(2): 244-252.

[40] Panagiotakos T. B., Fardis M. N. Deformations of Reinforced Concrete Members at Yielding and Ultimate. ACI Structural Journal, 2001; 98(2): 135-148.

[41] Decanini L., Liberatore, L., Mollaioli, F. Strength and stiffness reduction factors for infilled frames with openings. Earthquake Engineering and Engineering Vibration. 2014; 13: 437-454.

[42] Tubaldi, E; Freddi, F; Zona, A; Dall'Asta, A; (2019) Non-Dimensional Parametric Analysis for the Seismic Response of Dual Moment-Resisting and Buckling-Restrained Braced Frames. In: Conference on Earthquake \& Civil Engineering Dynamics (SECED 2019) Proceedings. SECED: London, UK.

[43] Tremblay R., Poncet L., Bolduc P., Neville R., DeVall R. (2004). Testing and design of buckling restrained braces for Canadian application. Proceeding of the $13^{\text {th }}$ World Conference on Earthquake Engineering, Vancouver, Canada.

[44] Hajirasouliha I., Doostan A. (2010). A simplified model for seismic response prediction of concentrically braced frames, Advances in Engineering Software, 41 (3): 497-505.

[45] Yue, Y., Chen, T., Bai, Y., Lu, X., Wang, Y., \& Musanyufu, J. (2019). Seismic design and analysis of reinforced concrete buckling-restrained braced frame buildings with multiperformance criteria. International Journal of Distributed Sensor Networks, 15(10), 1550147719881355.

[46] Bertero RD, Bertero VV. Performance-based seismic engineering: the need for a reliable conceptual comprehensive approach. Earthquake Engineering and Structural Dynamics. 2002; 31: $627-652$.

[47] Cornell C.A., Krawinkler H. Progress and challenges in seismic performance assessment. PEER Center News. 2000; 4(1): 1-3.

[48] Aslani H, Miranda E. Probability-based seismic response analysis. Engineering Structures 2005; 27(8): 1151-1163.

[49] Porter KA. (2003). An overview of PEER's performance-based earthquake engineering methodology. Proceedings of the $9^{\text {th }}$ International Conference on Application of Statistics and Probability in Civil Engineering (ICASP9), San Francisco, California.

[50] Iervolino I., Cornell C.A. Record Selection for Nonlinear Seismic Analysis of Structures. Earthquake Spectra. 2005; 21(3): 685-713.

[51] Shome N, Cornell C.A., Bazzurro P., Carballo J.E. Earthquake, records, and nonlinear responses. Earthquake Spectra. 1998; 14(3): 469-500.

[52] Luco N., Cornell C.A. Structure-specific scalar intensity measures for near-source and ordinary earthquake ground motions. Earthquake Spectra. 2007; 23(2): 357-92.

[53] Pinto P.E., Giannini R., Franchin P. Seismic Reliability Analysis of Structures, IUSS Press, Pavia, Italy, 2003.

[54] Vamvatsikos D., Cornell CA. Incremental dynamic analysis. Earthquake Engineering and Structural Dynamics. 2002; 31(3): 491-514.

[55] PEER, Pacific Earthquake Engineering Research Center http://peer.berkeley.edu/

[56] ITACA, Italian Accelerometric Archive http://itaca.mi.ingv.it/ItacaNet/itaca10_links.htm

[57] ISESD, Internet-Site for European Strong-Motion Data http://www.isesd.hi.is/ESD_Local/frameset.htm

[58] Scozzese, F., Tubaldi, E., \& Dall'Asta, A. (2020). Assessment of the effectiveness of MultipleStripe Analysis by using a stochastic earthquake input model. Bulletin of Earthquake 


\section{Engineering, 18: 3167-3203.}

[59] Bazzurro P., Cornell C.A., Shome N, Carballo J.E. Three proposals for characterizing MDOF nonlinear seismic response. Journal of Structural Engineering. 1998, 124(11), 1281-1289.

[60] Castaldo P., Palazzo B., Della Vecchia P. Life-cycle cost and seismic reliability analysis of 3D systems equipped with FPS for different isolation degrees. Engineering Structures. 2016; 125: 349-363.

[61] Castaldo P., Alfano G. Seismic reliability-based design of hardening and softening structures isolated by double concave sliding devices, Soil Dynamics and Earthquake Engineering, 2020, 129,105930.

[62] http://esse1-gis.mi.ingv.it/s1_en.php

[63] Gkimprixis A., Tubaldi E., Douglas, J. Comparison of methods to develop risk-targeted seismic design maps. Bulletin of Earthquake Engineering, 2019, 17: 3727-3752.

[64] CEN - European Committee for Standardization. Eurocode: Basis of Structural Design. Brussels (EC0), 2006.

[65] Tubaldi E., Freddi F., Zona A., Dall'Asta A. (2017). Seismic Performance of Steel Dual Systems with BRBs and Moment-Resisting Frames. In $16^{\text {th }}$ ECEE, European Conf. Earthq. Eng., Thessaloniki, Greece.

[66] Lucchini A., Mollaioli F., Bazzurro P. Floor response spectra for bare and infilled reinforced concrete frames. Journal of Earthquake Engineering. 2014; 18(7): 1060-1082. 